UNIVERSIDADE DE SÃO PAULO

ESCOLA DE ENFERMAGEM

ISABEL YOVANA QUISPE MENDOZA

PACIENTE IDOSO CIRÚRGICO: COMPLICAÇÕES NO PERIODO DE RECUPERAÇÃO PÓS-ANESTÉSICA 
ISABEL YOVANA QUISPE MENDOZA

\title{
PACIENTE IDOSO CIRÚRGICO: COMPLICAÇÕES NO PERÍODO DE RECUPERAÇÃO PÓS-ANESTÉSICA
}

\author{
Dissertação apresentada à Escola de \\ Enfermagem da Universidade de São Paulo \\ para obtenção do título de Mestre em \\ Enfermagem \\ Área de concentração: \\ Saúde do Adulto e Idoso \\ Orientadora: \\ Prof ${ }^{\text {a }}$ Dr. ${ }^{a}$ Aparecida de Cássia Giani \\ Peniche
}

São Paulo

2006 
Catalogação na Publicação (CIP)

Biblioteca "Wanda de Aguiar Horta"

\section{Escola de Enfermagem da Universidade de São Paulo}

Mendoza, Isabel Yovana Quispe.

Paciente idoso cirúrgico: complicações no período de recuperação pós-anestésica/ Isabel Yovana Quispe Mendoza. - São Paulo: I. Y. Q. Mendoza, 2006.

$104 \mathrm{p}$.

Dissertação (Mestrado) - Escola de Enfermagem da Universidade de São Paulo.

Orientadora: Prof ${ }^{a}$ Dr $^{a}$ Aparecida de Cássia Giani Peniche.

1. Complicações pós-operatórias 2. Idosos 3. Enfermagem perioperatória. I. Título. 
A meus pais, Mercedes Mendoza Bedoya e Policarpio Quispe Colque e, a minha irmã Mirian G. Quispe

Mendoza.

Vocês, que sempre estiveram comigo, oferecendo-me incondicional apoio, incentivo e amor. Obrigada por poder contar sempre com vocês. 
A professora e orientadora Dr $r^{a}$. Aparecida de Cássia Giani Peniche, pelo acolhimento e oportunidade que possibilitaram meu crescimento, pela paciência, compreensão e por disponibilizar sempre um tempo, mesmo diante de muitas atividades. 
AGRADECIMENTOS ESPECIAIS

À profa Dra. Rita de Cássia Burgos de Oliveira Leite, pelo apoio durante a etapa inicial desta pesquisa. Ao Antonio Jose de Melo, pelo apoio, incentivo e por compartilhar esta etapa da minha vida. 


\section{AGRADECIMENTOS}

Ao Hospital Universitário da Universidade de São Paulo (HU-USP) por permitir a realização desta pesquisa

Às professoras do curso de Pós-Graduação da Escola de Enfermagem da USP, pelos conhecimentos transmitidos durante esses anos.

A prof ${ }^{a}$. Dra ${ }^{a}$. Estela Regina Ferraz Bianchi e prof ${ }^{a}$ Dra. Rita de Cássia de Oliveira Leite pelas sugestões propostas no exame de qualificą̧ão.

A Márcia Zotti, pela solidariedade e amizade compartilhada todo este tempo.

À Dra Eutália Aparecida Cândido de Araújo pelo tratamento estatístico dos dados.

A todos aqueles que, direta ou indiretamente contribuíram para a realização deste trabalho. 
Mendoza IYQ. Paciente idoso cirúrgico: complicações no período de recuperação pós-anestésica. [dissertação]. São Paulo (SP): Escola de Enfermagem da Universidade de São Paulo; 2006.

\section{RESUMO}

Este estudo tem como objetivos, identificar os fatores de risco de maior incidência no paciente idoso cirúrgico nos períodos pré-operatório e intra-operatório, identificar as complicações mais freqüentes no paciente idoso cirúrgico no período de recuperação pós-anestésica e relacionar as complicações mais freqüentes do paciente idoso cirúrgico no período de recuperação pós-anestésica aos fatores de risco de maior incidência do paciente idoso cirúrgico nos períodos pré-operatório e intra-operatório. A amostra foi constituído por 110 prontuários de pacientes idosos submetidos a cirurgia durante o ano 2004, que obedeciam os seguintes critérios de inclusão: idosos de ambos sexos, idosos submetidos a cirurgias eletivas, de emergência e urgência. Procedeu-se à coleta de dados, utilizando-se um formulário, a fim de contemplar os objetivos deste estudo. Os resultados mostraram que, $62(56,4 \%)$ eram do sexo masculino; 63 (57,3\%) pacientes estavam na faixa etária de 70 a 79 anos; $36(32,7 \%)$ com hipertensão arterial sistêmica; $66(60 \%)$ classificados como ASA II. Referente a fatores de risco relacionado ao período intraoperatório, em $69(62,7 \%)$ pacientes o tempo de cirurgia foi inferior a três horas; 90 pacientes $(81,8 \%)$ foram posicionados em decúbito dorsal horizontal na mesa cirúrgica; 59 pacientes $(53,6 \%)$ foram submetidos à cirurgia abdominal e $56(50,9 \%)$ idosos foram submetidos à anestesia geral. Quanto às complicações na sala de recuperação pós-anestésica: $(55,5 \%)$ apresentaram hipotermia, $48(43,6 \%)$ dor e $40(36,4 \%)$ desenvolveram hipertensão arterial no período pós-operatório. De acordo com os resultados da análise de regressão logística, o sexo masculino e feminino apresentou associação estatisticamente significante com todas as complicações na sala recuperação pósanestésica, evidenciou-se, maior associação entre os idosos de 70 a 79 anos com a apresentação de dispnéia $(\mathrm{OR}=2,78)$ e idosos de 80 a 89 anos apresentou maior associação com taquicardia $(\mathrm{OR}=1,40)$. Não se obteve associação entre os idosos com idade acima de 90 anos com as complicações investigadas. Quanto à hipertensão arterial, o estágio II obteve maior associação com bradicardia $(\mathrm{OR}=8,01)$; assim como o escore ASA categorias II e III incrementam a possibilidade de apresentar hipertensão arterial no período de recuperação pós-anestésica $(\mathrm{OR}=4,79 ; 10,71)$ respectivamente,. Em relação à associação entre as complicações mais freqüentes na recuperação pós-anestésica com os fatores de risco relacionados ao paciente cirúrgico idoso no período intra-operatório, o tempo de cirurgia superior a cinco horas teve maior associação com hipertensão arterial $(\mathrm{OR}=6,49)$ quando comparado às cirurgias com duração entre 3 a 5 horas e inferior a 3 horas. A posição decúbito lateral apresentou maior associação com hipotermia, náusea, vômito e dor $(\mathrm{OR}=$ $6,68 ; 5,79 ; 3,12)$, respectivamente, quando comparado às posições decúbito dorsal horizontal e litotômica. Dentre os tipos de cirurgia, a artroplastia teve maior associação com náusea e vômito $(\mathrm{OR}=7,64)$ seguida de redução de fratura com taquicardia e dor $(\mathrm{OR}=3,71$ e 2,05), respectivamente. Quando realizada a associação entre o tipo de anestesia e complicações na recuperação pós-anestésica ,a 
anestesia raquidiana apresentou maior associação com taquicardia $(\mathrm{OR}=4,24)$, quando comparada à anestesia geral e peridural. Sendo assim, os pacientes idosos constituem-se em um desafio para a equipe de saúde em sala de recuperação pósanestésica, os quais devem levar em conta a alta prevalência de doenças associadas e as alterações funcionais decorrentes do processo de envelhecimento. 
Mendoza IYQ. Aging surgical patient: complications in the post-anesthetic recovery. [thesis]. São Paulo (SP): Escola de Enfermagem da Universidade de São Paulo; 2006.

\section{ABSTRACT}

This study has as its goals to identify the most common risk factors for aging surgical patients in the pre-operatory and intra-operatory periods; to identify the most frequent complications in aging surgical patients in the post-anesthetic period; and make the relation between the most frequent complications in the post-anesthetic period for aging surgical patients with the most common risk factors in the preoperatory and intra-operatory periods. The sample was comprised of 110 records of aging patients submitted to surgery during 2004, which complied with the following inclusion criteria: aging of both sex; aging submitted to elective, emergency and urgency. Data was gathered through a form that includes socio-demographic data, aspects related to the patient, aspects related to the intra-operatory period, and aspects related to the complications in the post-anesthetic recovery. The results showed that $62(56.4 \%)$ patients were male; $63(57.3 \%)$ were in the age group from 70 to 79 years old; $36(32.7 \%)$ suffered from systemic artery hypertension; $66(60 \%)$ classified as ASA II. Concerning the risk factors related to the intra-operatory period, in $69(62.7 \%)$ patients surgery time was under three hours; 90 patients $(81.8 \%)$ were positioned lying on the side on the operation table; 59 patients $(53.6 \%)$ underwent abdominal surgery; and $56(50.9 \%)$ patients had general anesthesia. In regards to complications in the post-anesthetic recovery room: (55.5\%) experienced hypothermia, 48 (43.6\%), pain, and $40(36.4 \%)$ developed artery hypertension in the post-operatory period. According to the result of the logistics regression analysis, males and females showed statistically significant association with all the complications in the post-anesthetic recovery room; it was evidenced more association among the aged from 70 to 79 years old with dyspnea $(\mathrm{OR}=2.78)$, while patients from 80 to 89 years old had more association with tachycardia $(\mathrm{OR}=1.40)$. There was no association among patients older than 90 with the researched complications. Regarding artery hypertension, stage II got more association with bradycardia ( $\mathrm{OR}=8.01)$; as the ASA score categories II and III increase the possibility of presenting artery hypertension in the post-anesthetic recovery period $(\mathrm{OR}=4.79 ;$ 10.71 $)$ respectively. Regarding the association between the most frequent complications in the post-anesthetic recovery with the risk factors related to aging surgery patients in the intra-operatory period, surgery time exceeding five hours had more association with artery hypertension $(\mathrm{OR}=6.49)$ when compared with 3 to 5 hour-surgeries and less than 3-hour surgeries. The lateral decubitus position showed more association with hypothermia, nausea, vomiting and pain $(\mathrm{OR}=6.68 ; 5.79$; 3.12 ), respectively, when compared with the lying horizontally on the side and lithotomic positions. Among the types of surgeries, arthroplasty had more association with nausea and vomit $(\mathrm{OR}=7.64)$, followed by fracture reduction with tachycardia and pain $(\mathrm{OR}=3.71$ and 2.05), respectively. When the association between the kind of anesthesia and complications in the post-anesthetic recovery is made, rachidian showed more association with tachycardia $(\mathrm{OR}=4.24)$, when compared with general 
anesthesia and peridural. Thus aging patients in the post-anesthetic recovery period are a challenge for the health team, which must take into account the high prevalence of associated diseases and the functional alterations resulting from the aging process.

Key words: Aged; Perioperative Nursing; Anesthesia Recovery Period; PostOperatory Complications. 


\section{LISTA DE ABREVIATURAS}

Organização das Nações Unidas.............................................................. ONU

Centro Cirúrgico ............................................................................... CC

Sistema de Assistência de Enfermagem Perioperatória............................... SAEP

Sistema de Assistência de Enfermagem..................................................... SAE

Sala de Recuperação Pós-Anestésica............................................................. SRPA

Recuperação Pós-Anestésica........................................................................ RPA

Hipertensão Arterial Sistêmica.................................................................. HAS

Joint National Commitee................................................................ JNC

Americam Society of Anesthesiologist.............................. ASA

Infecção do sitio cirúrgico........................................................................ ISC

Circulação extracorpórea............................................................................. CEC

Hospital Universitário.......................................................................... HU

Universidade de São Paulo............................................................................. USP 
Sistema Integrado de Saúde da Universidade de São Paulo.

SI-USP

Sistema Único de Saúde........................................................................ SUS

Programa de Assistência Domiciliaria........................................................... PAD

Comitê de Ética em Pesquisa.................................................................... CEP

Serviço de Arquivo Médico e Estatística.............................................. SAME

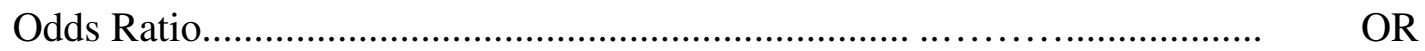

Estados Unidos da América..................................................................... EUA

Pressão Arterial..................................................................................... PA

Sistema Nervoso Central........................................................................ SNC

Antiinflamatórios não esteróides........................................................... NAIDs

Escala Visual Analógica............................................................................ EVA

Índice de Massa Corpórea..................................................................... IMC

Pressão Intraocular .......................................................................... PIO 


\section{LISTA DE TABELAS}

TABELA 1 - Distribuição Sumáriodos fatores de risco: sexo, idade, patologias de base, e ASA, relacionados ao paciente idoso cirúrgico no período préoperatório. São Paulo 2006

TABELA 2 - Distribuição dos fatores de risco: tempo de cirurgia, tipo de cirurgia, posição cirúrgica e tipo de anestesia relacionada ao paciente idoso no período intra-operatório. São Paulo-2006 48

TABELA 3 - Distribuição das complicações mais freqüentes na sala de recuperação pós-anestésica relacionada ao paciente idoso cirúrgico. São Paulo 2006 .49

TABELA 4 - Associação entre as complicações mais freqüentes em sala de recuperação pós-anestésica e fatores de risco relacionado ao paciente idoso cirúrgico no período pré-operatório. São Paulo 2006

TABELA 5 - Associação entre as complicações mais freqüentes em sala de recuperação pós-anestésica e fatores de risco relacionados ao paciente idoso cirúrgico no período intra-operatório. São Paulo 2006 


\section{LISTA DE QUADROS}

QUADRO 1- Classificação da hipertensão arterial segundo o Comitê de União

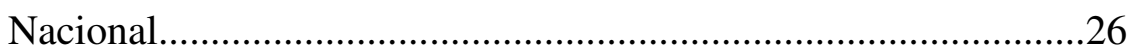

QUADRO 2 - Classificação da condição clínica do paciente, segundo a Sociedade Americana de Anestesiologistas (ASA). 


\section{SUMÁRIO}

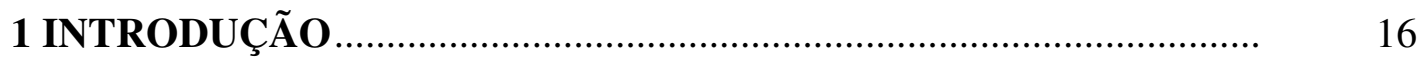

1.1 Assistência de Enfermagem Perioperatória ......................................... 18

1.2 Fatores de risco e complicações pós-operatórias.................................... 22

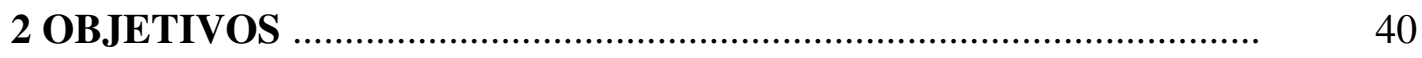

3 MATERIAL E MÉTODO.............................................................. 42

3.1 Tipo de estudo.................................................................... 42

3.2 Local do estudo ...................................................................... 42

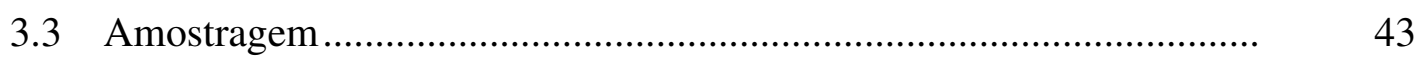

$3.4 \quad 3.3 .1$ Critérios de inclusão ............................................................. 43

3.4 Instrumento de coleta de dados...........................................................

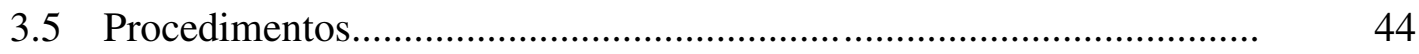

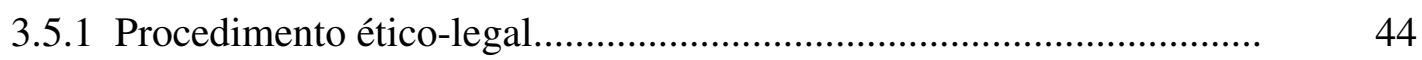

3.5.2 Procedimentos de coleta de dados.................................................... 44

3.5.3 Procedimento de análise dos dados.................................................. 45

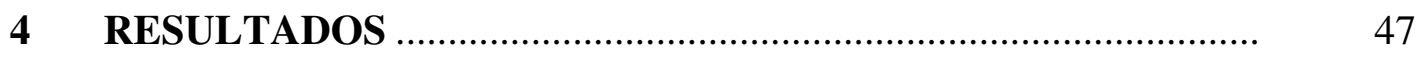

5 DISCUSSÃO

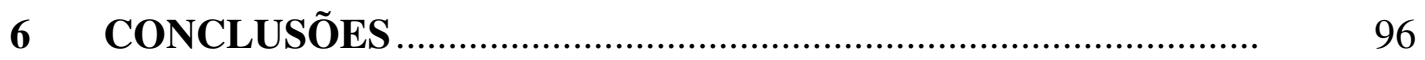

REFERÊNCIAS

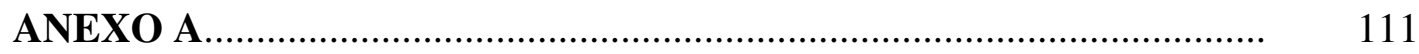

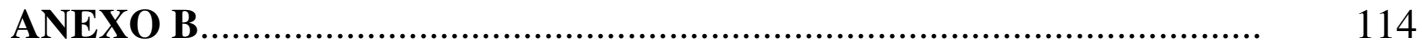





\section{Introdução}




\section{INTRODUÇÃO}

A vida é um processo no qual podem ser distinguidas fases, como: infância, puberdade, maturidade e envelhecimento em que podem ser evidenciados marcadores biofisiológicos entre uma fase e outra ${ }^{(\mathbf{1})}$.

Assim, o envelhecimento é um processo multidimensional que pode ser definido, segundo perspectiva biológica, social, intelectual, econômica, funcional e cronológica, sendo a última a mais utilizada ${ }^{(2)}$. Com base nesse critério, a Organização das Nações Unidas $(\mathrm{ONU})^{(3)}$ considera idoso a pessoa com 65 anos ou mais, nos paises desenvolvidos e com 60 anos de idade, nos paises em desenvolvimento.

Hoje, o segmento idoso envolve um intervalo etário amplo, uma vez que pode atingir os 120 anos. No cenário atual, conforme a região do mundo a probabilidade de sobrevivência a partir dos sessenta anos vem aumentando progressivamente.

Este crescimento começou a ser evidente nas décadas passadas nos países desenvolvidos, sobretudo na Europa (28\% acima de 70 anos), onde foi constatado um crescimento populacional de quatro vezes, enquanto o total de idosos cresceu 16 vezes no mesmo período. Nos países em desenvolvimento, nos quais se inclui o Brasil, este crescimento apresenta-se de forma surpreendente, isto é, em 2025, o pais terá a sexta população mais velha do mundo com 32 milhões de pessoas idosas ${ }^{(4,5,6)}$.

Na América Latina e Caribe, a maioria dos países encontra-se em uma fase intermediária de transição demográfica. Para Palloni e Peláez ${ }^{(7)}$, tal 
fenômeno apresenta características únicas ou combinadas dentro de um contexto institucional instável e um ambiente econômico desfavorável que fazem com que este processo seja mais complicado do que em outras áreas do mundo.

Se por um lado, o envelhecimento populacional trouxe benefícios de maior longevidade; por outro, mostrou um novo perfil de morbidade e mortalidade, caracterizado por um aumento de doenças crônicas não infecciosas e, consequientemente, os países enfrentaram novas situações, entre as quais se destacam: mudanças na estrutura social, econômica e cultural, acarretando novos olhares e planejamentos para contemplarem suas expectativas de saúde, bem como atender às demandas biopsicossociais dessa população ${ }^{(4,8)}$.

Para este novo quadro, contribui a queda nas taxas de fecundidade e mais recentemente na diminuição da mortalidade acima de 60 anos. Além disso, o aumento da população idosa atribúi-se, sobretudo à maior utilização da tecnologia de saúde que reduziu a exposição a doenças infecciosas e proporcionou melhor tratamento e recuperação mais rápida dos doentes, diminuindo significativamente a mortalidade. Estas três características proporcionaram o aumento expressivo da população idosa ${ }^{(7)}$.

Com o crescente aumento da expectativa de vida, é cada vez maior o número de pessoas idosas que necessitam de algum tipo de procedimento cirúrgico.

Como já foi mencionado, o envelhecimento é um processo multidimensional, complexo que dificilmente pode ser abordado em sua totalidade. No presente estudo, não se pretende esgotar o tema do envelhecimento como um todo e, sim, entender como este fenômeno ocorre no contexto cirúrgico. 


\subsection{ASSISTÊNCIA DE ENFERMAGEM PERIOPERATÓRIA}

O Centro Cirúrgico (CC) é considerado um setor importante e crítico dentro de um hospital, devendo oferecer as condições necessárias à execução dos procedimentos complexos ali realizados. É um local onde a iminência de uma cirurgia desencadeia uma série de repercussões ao indivíduo e, em especial, ao $\operatorname{idoso}^{(9)}$.

Além de ser importante e crítica, esta unidade é identificada como uma fonte geradora de recursos e despesas de hospital, requer um gerente de enfermagem que identifique problemas, estabeleça diagnóstico, faça o planejamento e sobretudo avalie as atividades, ou seja, estabeleça uma sistematização da assistência de enfermagem nesta unidade ${ }^{(9,10)}$.

Nesse sentido, no Brasil dispõe-se do Sistema de Assistência de Enfermagem Perioperatório (SAEP), pautado no Sistema de Assistência de Enfermagem (SAE), e com um enfoque específico ao paciente cirúrgico. O SAEP abrange o conceito de assistência, tanto na área de atuação técnica como expressiva ${ }^{(11)}$.

É um método que tem como foco o paciente e as intervenções visam a atender suas necessidades. O SAEP é a metodologia utilizada para descrever as várias etapas de uma experiência cirúrgica ${ }^{(11)}$.

A implantação desta sistematização está direcionada a necessidade de planejar as ações, determinar e gerenciar os cuidados, registrar o que foi planejado e executado e, finalmente, avaliar estas ações, permitindo assim brindar assistência com qualidade ao paciente idoso no âmbito perioperatório ${ }^{(11)}$. 
A palavra perioperatória incorpora os três períodos da cirurgia: pré-operatório, intra-operatório e pós-operatória. Assim, a fase pré-operatória, como primeira, iniciase com a decisão de efetuar a internação cirúrgica e termina com o transporte do paciente até o CC. Durante esse tempo, o enfermeiro realiza diversas atividades, como a visita pré-operatória, pois é por meio desta que ele identifica problemas, prepara o paciente físico, emocional e psicologicamente com a finalidade de aliviar e diminuir a ansiedade. Ao mesmo tempo, constitui-se em uma estratégia que permite identificar e avaliar as necessidades, tanto do paciente como da família, viabilizando uma assistência integral, documentada e contínua em todo o período perioperatório $^{(12)}$.

Apesar da internação dos pacientes submetidos a procedimentos cirúrgicos ocorrer muitas vezes poucas horas antes das cirurgias, é conveniente ressaltar que a orientação prévia desses pacientes pelo enfermeiro contribui para a prevenção de complicações pós-operatórias. Nesse sentido, contar com o respaldo da instituição possibilita ao enfermeiro organizar um serviço que ofereça um atendimento diferenciado ao paciente idoso ${ }^{(13)}$.

Na segunda fase, ou seja, o transoperatório, a enfermeira desenvolve atividades que vão desde a preparação e provisão da sala cirúrgica até a monitorização do paciente. Esta última tem a finalidade de implementar cuidados como: prevenir ventilação inadequada; infiltração de líquidos infundidos, prever sinais de hipertermia ou prevenir a hipotermia. Durante a cirurgia, a monitorização é essencial para prevenir complicações, tanto no período intra-operatório como na sala de recuperação pós-anestésica (SRPA) ${ }^{(14)}$. 
Cabe ressaltar que a assistência ao idoso em situação cirúrgica difere da atenção que recebem outros grupos etários; pois, as próprias mudanças decorrentes do processo de envelhecimento e da presença de doenças associadas podem comprometer o equilíbrio funcional e aumentar a vulnerabilidade dos idosos de apresentar complicações pós-operatórias ${ }^{(15)}$.

Leite $^{(16)}$ identifica que são poucos os enfermeiros que realizam procedimentos diferenciados para com o paciente idoso. Além disso, pouca informação é fornecida sobre o período transoperatório, momento crítico do processo cirúrgico, sobretudo ao paciente idoso, para quem a cirurgia está cercada de mitos reais e irreais que precisam ser bem explorados e trabalhados. Da mesma forma, Protti ${ }^{(17)}$ refere que o enfermeiro não presta atendimento diferenciado ao idoso. Infelizmente esta concepção ainda se constitui na forma de atuar de alguns profissionais. Segundo Leite $^{(16)}$, o idoso deve ser considerado como um paciente comum, no que se refere aos direitos e obrigações de ser atendido com competência técnica, dignidade e atenção profissional, mas, como um paciente diferenciado, no que se refere aos aspectos fisiológicos e psicológicos que apresenta alterações inerentes ao processo normal de envelhecimento ${ }^{(16)}$.

$\mathrm{O}$ fato exige que o enfermeiro tenha conhecimentos do processo de envelhecimento humano que associado aos conhecimentos técnicos, científicos, humanísticos, éticos, e sociais, entre outros, diferenciam o cuidar ${ }^{(18)}$.

A implantação da sistematização das ações de enfermagem tem contribuído no registro e documentação das ocorrências e procedimentos realizados. A documentação perioperatória é essencial para a continuidade do cuidado ao paciente e para comparações entre os resultados obtidos e os esperados na assistência ${ }^{(19)}$. 
Entretanto, Leite ${ }^{(16)}$ afirma que a comunicação representa um sério problema na assistência de enfermagem, pois, os enfermeiros não a utilizam da forma escrita para registrar dados pertinentes aos pacientes, o que favorece a descontinuidade da assistência prestada pelo profissional em todo o processo cirúrgico.

Assim qualquer tipo de informação, além de ser verbalizada, é preciso que esteja registrada no prontuário do paciente ou em registros de enfermagem, como uma forma de prevenção de maus entendidos e também de proteção legal $^{(20)}$.

A terceira fase do SAEP, ou seja, o período pós-operatório compreende todo o intervalo existente entre o final da anestesia até 24 a 48 horas após a realização do procedimento anestésico-cirúrgico, e subdivide-se em três etapas: a recuperação pósanestésica, o pós-operatório imediato e o pós-operatório tardio ${ }^{(10)}$.

No presente estudo, aborda-se a etapa de recuperação pós-anestésica, (RPA), período que se inicia com o encaminhamento do paciente da sala de operação, ao final da anestesia, para a sala recuperação pós-anestésica pelo anestesiologista, pelo enfermeiro, técnico ou auxiliar de enfermagem. O que se subentende ser um transporte seguro do paciente, mesmo que a unidade de recuperação pós-anestésica seja uma área muita próxima à sala de operações ${ }^{(12)}$.

Nesta etapa, o indivíduo encontra-se em uma fase de vulnerabilidade e instabilidade. Em consequiência disto poderão surgir alterações que, nesse momento, podem ser percebidas por meio de observações clínicas e das medidas de parâmetros vitais que irão refletir as condições do paciente ${ }^{(21)}$.

Os cuidados adequados para cada idoso dependem do conhecimento de doenças preexistentes, do procedimento cirúrgico a ser realizado, das implicações farmacológicas dos agentes anestésicos utilizados e da avaliação das condições 
fisiológicas do mesmo na SRPA, isto é, avaliação da respiração, pressão arterial, oximetria de pulso (saturação de oxigênio), atividade muscular e nível de consciência ${ }^{(22)}$.

\subsection{FATORES DE RISCO RELACIONADOS AO PERÍODO PRÉ E INTRA- OPERATÓRIO}

Fatores de risco são definidos como características individuais inatas ou adquiridas, que determinam uma alta probabilidade de desenvolver certo evento relacionado à saúde, em um determinado tempo. Esses fatores, quando identificados previamente ao evento a que estão associados, muitas vezes, podem ser tratados ou modificados por ações de saúde, como uma forma preventiva de manter a saúde, a probabilidade de eventos mórbidos ou fatais ${ }^{(23)}$.

No contexto de CC, pode-se mencionar que os fatores de risco são definidos, como variáveis isoladas ou agrupadas, presentes no período perioperatório e que se associam à ocorrência de complicações, sejam elas cardíacas, pulmonares ou de qualquer outra natureza ${ }^{(24,25)}$.

Complicações pós-operatórias é o termo utilizado para descrever eventos que se desenvolvem após um procedimento, tratamento ou doença. Elas estão ligadas direta ou indiretamente aos procedimentos (risco de procedimentos), tratamentos (efeitos colaterais ou toxicidade) ou doenças ${ }^{(26)}$.

Cooper, apud Shauna ${ }^{(27)}$, em seu estudo sobre complicações na SRPA, mostrou uma incidência de $10 \%$ a $18 \%$ de eventos de impacto em SRPA e os definiu como 
“efeitos não antecipados e indesejáveis relacionados com a anestesia que requerem uma intervenção".

No estudo de Mayson ${ }^{(28)}$, resultados mostraram a ocorrência de reações adversas na sala de cirurgia relacionadas com a extubação do paciente $(5,8 \%)$, destas, a hipoventilação (2\%) se apresentou com maior freqüência. Já na SRPA as complicações mais comuns foram hipotensão $(4,5 \%)$, hipertensão $(4,3 \%)$ e arritmias (2.8\%). Neste estudo o autor conceitua como complicação todo evento que tem impacto na recuperação anestésica do paciente.

Segundo Haddawai et al. ${ }^{(29)}$ em razão do aumento da demanda de cirurgias na população idosa, complicações relacionadas ao sistema cardiovascular e respiratório, vêm sendo estudadas com ênfase, pois alguns autores acreditam que, em pessoas com 60 anos ou mais de idade, o risco de um procedimento cirúrgico é três vezes maior do que na população jovem, especialmente, em situações de emergência

Gonzáles $^{(30)}$ constata que existe uma probabilidade maior de complicações e de mortalidade na SRPA quando as cirurgias são praticadas de urgência associadas a uma patologia maligna.

Esta situação é freqüente para o idoso, pois pela percepção alterada dos sintomas retarda não só o diagnóstico como também a terapêutica cirúrgica o que ocasiona com muita freqüência a cirurgia de urgência ${ }^{(31)}$.

As intervenções cirúrgicas em pacientes de idade avançada foram por muito tempo vistas com pessimismo, representando a velhice um obstáculo intransponível e desanimador à terapêutica cirúrgica. Os fenômenos próprios do envelhecimento eram encarados, como entidades mórbidas, para os quais a ciência era impotente ${ }^{(32)}$. 
Embora a ocorrência de complicações pós-operatórias seja maior em pacientes idosos, existem algumas evidências de que a idade não é propriamente um fator de risco independente. Isto indica que a mortalidade de indivíduos idosos está mais relacionada com alterações fisiológicas e com a condição clínica do paciente do que com sua idade cronológica ${ }^{(24)}$.

Portanto, a idade já não deve ser mais uma justificativa adotada pelo cirurgião, para a não realização da cirurgia, uma vez que, atualmente, se dispõe de novos e diversos equipamentos para realizar cirurgias complexas. Os avanços nas técnicas cirúrgicas, procedimentos e agentes anestésicos fazem as cirurgias menos perigosas, e os cirurgiões são, geralmente, mais cautelosos para operar pacientes idosos por considerarem que estes são frágeis pela diminuição de reserva fisiológica ${ }^{(29)}$.

A velhice é caracterizada pelo declínio das funções orgânicas expressas pela dificuldade do organismo em se adaptar às condições de sobrecarga funcional. Essas alterações são, portanto, conseqüências do envelhecimento ${ }^{(1)}$.

Pela presença dessas alterações, os pacientes idosos representam um grupo etário considerado de alto risco. Geralmente são pacientes que apresentam uma maior co-morbidade e, ao mesmo tempo, são mais vulneráveis a complicações quando comparados com a população geral ${ }^{(33)}$.

Sendo assim, detectar doenças clínicas preexistentes nos idosos permite avaliar a possibilidade de corrigí-las em tempo hábil para a cirurgia. Nas cirurgias de emergência, esta avaliação não é possível; portanto, a probabilidade da disfunção de um órgão é alta. Nestes casos, as complicações cardíacas e pulmonares são as principais responsáveis por cerca de $60 \%$ da mortalidade, após a cirurgia de 
urgência. Portanto, sempre que possível deve ser realizada uma avaliação préoperatória $^{(4)}$.

Com o envelhecimento, ocorrem alterações cardíacas com modificações celulares e bioquímicas, ocasionando espessamento da parede do ventrículo esquerdo, com diminuição das fibras condutoras de estímulos e redução do número de células do nó sinusal. Como conseqüência destas alterações celulares, temos a diminuição da eficiência contrátil e de resposta ao estresse, aumento do período de relaxamento cardíaco e espessamento das células miocárdicas, do tecido conectivo e das válvulas cardíacas.

Estas importantes modificações terão repercussões significantes sobre o rendimento cardíaco. A contratilidade diminui, o tempo de contração miocárdica aumenta e a velocidade de contração, por conseqüência, cai.

Por outro lado, alterações no nível do sistema nervoso autônomo são representadas pela queda da sensibilidade dos receptores adrenérgicos. O reflexo barorreceptor fica lento, repercutindo na pressão arterial sistêmica que é agravada por ocasião do uso de diuréticos, na menor oferta de fluidos e em alterações posturais, podendo acarretar depressão no nó sinusal e, conseqüentemente, síncope $^{(34)}$.

Em consequiência deste quadro, surgirão doenças associadas às alterações já mencionadas. A hipertensão arterial sistêmica (HAS) é a doença crônica mais comum entre os idosos, e sua prevalência aumenta progressivamente com a idade. Eleva o custo médico-social, sobretudo pelas suas complicações, assim como as doenças cerebrovasculares, arterial coronária e vascular de extremidades, além da insuficiência cardíaca e da insuficiência renal crônica ${ }^{(35)}$. 
Para o diagnóstico de hipertensão, é preciso conhecer os parâmetros normais. Sendo assim, o recente trabalho da VII Joint National Commitee (VII JNC) ${ }^{(36)}$, sobre prevenção, detecção, avaliação e tratamento da Pressão Sangüínea Alta publicou uma nova classificação da HAS, ou seja, a situação dita de "pré-hipertensão". As modificações do estilo de vida devem ser incentivadas, tendo em vista a grande possibilidade de evolução futura para o estado de hipertensão arterial com o avançar da idade.

Quadro 1- Classificação da hipertensão arterial, segundo o Comitê de União Nacional sobre prevenção, detecção, avaliação e tratamento da Pressão Sangüínea Alta.

\begin{tabular}{|l|l|}
\hline \multicolumn{1}{|c|}{ Nível da Pressão Arterial } & \multicolumn{1}{c|}{ Classificação } \\
\hline$<120$ sistólica e $<80$ diastólica & Normal. \\
\hline$<=139$ sistólica e $<=89$ diastólica & Pré-Hipertensão. \\
\hline $140-159$ sistólica ou $90-99$ diastólica & Hipertensão Estágio 1. \\
\hline$>160$ sistólica ou $>100$ diastólica & Hipertensão Estágio 2. \\
\hline
\end{tabular}

A intenção dessa nova classificação é mostrar a importância da necessidade de se diagnosticar precocemente a hipertensão e mantê-la em nível o mais fisiológico possível, tendo em vista o enorme risco cardiovascular que a mesma apresenta ao indivíduo ${ }^{(36)}$.

No que se refere ao sistema respiratório, com o progredir da idade, ocorrem significativas alterações estruturais na caixa torácica: diminuição do diâmetro das vias aéreas de pequeno calibre, o que resulta em aumento da resistência final das vias aéreas, independentes de qualquer alteração prévia, seja de caráter enfisematoso ou 
de lesão bronquiolar. Além disto, há alteração na morfologia de sacos alveolares que se tornam menos profundos. Estas alterações resultam da diminuição das fibras elásticas e aumento do tecido de colágeno ${ }^{(37)}$.

Em virtude de modificações anatômicas no idoso, as seguintes alterações fisiológicas podem apresentar-se, como: diminuição da retração elástica do tecido pulmonar, da capacidade de difusão de oxigênio, oclusão prematura de pequenas vias aéreas, aumento do gradiente alvéolo-arterial de oxigênio e diminuição do fluxo expiratório $^{(34)}$.

Além da perda funcional pela idade, outros fatores podem contribuir para o prejuízo da função pulmonar, como o fumo, doenças pulmonares obstrutivas e exposição ambiental a poluentes. Nos tabagistas, por exemplo, apresenta-se a redução dos reflexos laríngeos de proteção que aumentam o risco para aspiração traqueobrônquica do conteúdo gástrico ou secreções nasofaríngeas ${ }^{(38)}$.

Na prática clínica, os fatores de co-morbidade são classificados, segundo o escore da Americam Society of Anesthesiologist (ASA), considerado um índice de risco perioperatório que descreve o estado físico do paciente antes da cirurgia.

Quadro 2- Classificação do estado físico do paciente, segundo a Sociedade Americana de Anestesiologistas (ASA). 


\begin{tabular}{|c|c|}
\hline Classe & Descrição \\
\hline ASA 1 & Estado físico saudável do paciente. \\
\hline ASA 2 & $\begin{array}{l}\text { Presença de doença sistêmica moderada e não } \\
\text { incapacitante. }\end{array}$ \\
\hline ASA 3 & $\begin{array}{l}\text { Presença de doença sistêmica grave e não } \\
\text { incapacitante. }\end{array}$ \\
\hline $\begin{array}{l}\text { ASA } 4 \\
\text { ASA } 5\end{array}$ & $\begin{array}{l}\text { Presença de doença incapacitante, com ameaça a } \\
\text { vida. }\end{array}$ \\
\hline ASA 6 & $\begin{array}{l}\text { Moribundo, com pequena possibilidade de } \\
\text { sobreviver por mais de } 24 \text { horas com ou sem } \\
\text { cirurgia. } \\
\text { Paciente declarado com morte cerebral, cujos } \\
\text { órgãos estão sendo removidos para propósitos de } \\
\text { doação. }\end{array}$ \\
\hline
\end{tabular}

A nutrição constitui outro fator determinante, já que pacientes com déficits nutricionais toleram mal as cirurgias de grande porte e têm risco aumentado de sepse e mortalidade pós-operatória. Indivíduos que perderam rapidamente mais de $10 \%$ de seu peso usual ou têm uma história nutricional pobre, ou ainda, tenham estado incapacitados de se alimentar por duas semanas antes da cirurgia, possuem condições desfavoráveis para enfrentar situações de urgência. A contagem de linfócitos totais e os níveis séricos de albumina e transferrina fornecem dados importantes quanto ao estado nutricional $^{(39)}$.

Pode-se ainda argumentar que a capacidade do paciente de responder às necessidades energéticas exigidas pelo trauma, intervenção cirúrgica e estados infecciosos depende basicamente dos depósitos corpóreos de energia potencial e substratos bioquímicos ativos que podem variar, de acordo com a oferta, assimilação e utilização de nutrientes exógenos ${ }^{(40)}$. 
Se a desnutrição é considerada como fator de risco, a obesidade também constitui-se em um fator de risco comprovado para infecções, sobretudo no período transoperatório e na SRPA. Em razão da espessura do tecido gorduroso ter influência direta e proporcional nas taxas de infecção, esta susceptibilidade está relacionada à irrigação local de tecido adiposo pouco vascularizado e associada a maior duração do procedimento cirúrgico ${ }^{(41)}$.

Concordando com o anteriormente mencionado, no estudo de Oliveira ${ }^{(42)}$, a obesidade mostrou-se significativa às complicações pós-operatórias, como a ocorrência de infecção do sitio cirúrgico (ISC). A autora refere que este fato está relacionado com a pouca vascularização do tecido gorduroso, levando a procedimentos cirúrgicos mais demorados, a maior facilidade do trauma do tecido operado e dificuldades de se realizar uma hemóstase adequada.

Além dos fatores citados, é importante ressaltar que o ato anestésico cirúrgico desencadeia sentimentos, entre estes, o de ansiedade, definido como resposta emocional transitória, percebida pela consciência e caracterizada por sentimentos subjetivos de tensão, apreensão, nervosismo e preocupação, intensificando dessa forma a atividade do sistema nervoso autônomo ${ }^{(43)}$.

Assim, alterações hormonais causadas pela ansiedade podem manifestar-se de várias formas nos pacientes como: as oscilações da freqüência de pulso, pressão arterial, temperatura, dor, coloração e comportamento constituem-se em uma resposta fisiológica do organismo à agressão sofrida pelo trauma anestésicocirúrgico $^{(44)}$.

Acrescenta-se ainda que, pela complexidade existente na resposta dada pelo homem ao procedimento anestésico-cirúrgico, as alterações desses marcadores 
biológicos da ansiedade precisam ser interpretadas como o reflexo do paciente operado, ou seja, não só a dor que provoca alterações, como taquicardia ou aumento da pressão arterial, outros sintomas são decorrentes e potencializados pelos fatores ansiogênicos próprios do procedimento anestésico-cirúrgico ${ }^{(21)}$.

Quanto ao processo anestésico cirúrgico, por si só, é visto como um risco e particularmente considerando-se o paciente idoso, esta probabilidade é aumentada em decorrência das especificidades anatômicas e funcionais da idade.

Sem dúvida, a responsabilidade na indicação cirúrgica de um paciente cabe ao cirurgião. A escolha de um procedimento agressivo, lesivo que invada não só a integridade física, mas o aspecto emocional do ser humano é de suma complexidade. Embora, algumas vezes, o paciente idoso tenha como tratamento a escolha cirúrgica, cabe ao cirurgião ratificá-la ou contrariá-la, levando em consideração os critérios já mencionados na etapa pré-operatória. ${ }^{(45)}$.

No período transoperatório, o idoso é submetido à indução do agente anestésico, oxigenação e, muitas vezes, ao fluxo sangüíneo artificial e circulação extracorpórea (CEC), entre outros. Assim, durante a indução da anestesia, alguns procedimentos são necessários, como por exemplo a intubação, aspiração e fixação da cabeça, mas, que expolia o paciente ${ }^{(46)}$.

Neto; Fernandes ${ }^{(38)}$ referem que a anestesia e determinadas cirurgias predispõem a alterações na mecânica respiratória, volumes pulmonares e trocas gasosas, e são mais intensas com o avançar da idade, além de que estas alterações podem persistir no período pós-operatório, resultando em hipoxemia e predisposição à infecção pulmonar. 
No que se refere a alterações cardiovasculares, mais especificamente à pressão arterial, a indução anestésica deve respeitar a condição prévia do paciente, sem provocar alterações bruscas da pressão arterial que podem propiciar acidentes vasculares em órgãos nobres ${ }^{(40)}$.

Após a indução do agente anestésico, de acordo com o tipo de cirurgia, o paciente precisa ser colocado em diferentes posições para facilitar o procedimento cirúrgico e obter os resultados desejáveis. Este posicionamento é escolhido pelo cirurgião, determinado pelo procedimento cirúrgico, abordagem cirúrgica, tipo de anestésico, idade, altura e peso do paciente e seu estado geral ${ }^{(47)}$.

No posicionamento, deve-se assegurar que o paciente mantenha o correto alinhamento corporal, manutenção de boa função respiratória, de boa circulação, prevenção da pressão sobre músculos e nervos, boa exposição e acesso ao campo cirúrgico e bom acesso para administração de anestésicos e observação de seus efeitos $^{(48)}$.

Entre algumas das complicações freqüentes decorrentes de um mau posicionamento em sala cirúrgica, temos ${ }^{(49)}$ :

Cardiovasculares: hipotensão é a complicação cardiovascular mais comum, esta pode ser repentina e no paciente idoso pode precipitar um infarto do miocárdio.

Respiratório: ventilação/perfusão anormal pode ocorrer nas posições prona e lateral, especialmente, em pacientes obesos.

Dano de nervos periféricos: esta é uma das complicações mais comuns de posicionamento. Em estudos, verificaram-se danos do nervo plexo braquial que, freqüentemente, ocorrem nas posições prona, supina e lateral. Seguidos de danos do nervo perineal na posição supina. Fatores relevantes, como a posição superficial do 
nervo, o tempo da cirurgia e a prolongada pressão sobre as proeminências ósseas pode produzir danos desses nervos.

Outras complicações como a estase venosa pode levar a uma trombose venosa profunda; danos dos genitais femininos e masculinos podem ocorrer na posição supina. Similarmente, a pressão prolongada sobre os seios causa lesões importantes. Se o pescoço não for posicionado corretamente durante as posições supina e lateral, podem ocorrer prejuízos na base cervical. Os tecidos, ao redor da face, muitas vezes apresentam pontos de pressão pelo posicionamento incorreto especialmente se ficarem presos entre os dentes. Dano nos olhos é uma das mais sérias complicações de posicionamento, em especial, na posição prona que decorre da pressão exercida sobre os olhos do paciente sem a proteção necessária e correta.

Ainda é possível desencadear complicações com base em outros eventos, como a tricotomia que, em determinadas situações, é realizada na própria sala de operação. Existe a possibilidade de ocorrência que, varia desde uma inflamação folicular até cortes visíveis e sangrantes. Estes eventos advertem sobre a necessidade de proceder a tricotomia com cuidado no paciente idoso em razão de características próprias de sua pele ${ }^{(50)}$.

A anti-sepsia da pele, geralmente, é realizada com solução antimicrobiana, esta deve ser selecionada, considerando a sensibilidade do paciente e as condições de sua pele; evitando, dessa forma, reações adversas às desejadas. Os sítios cirúrgicos com pele traumatizada ou, em local sem pele, podem ser preparados apenas com solução salina isotônica. Para todos esses procedimentos, a extensão da área da pele a ser preparada deve ser suficiente para suprir toda a incisão prevista, atender as 
necessidades de colocação de drenos e movimentos inadvertidos de campos cirúrgicos durante o procedimento ${ }^{(50)}$.

Embora o tamanho da incisão cirúrgica esteja relacionado com a intensidade do trauma, não é o fator mais relevante na cirurgia do idoso e, por isso, não se devem realizar pequenas aberturas em detrimento de uma adequada exposição do campo operatório. A incisão deve ser suficiente para concretizar de modo seguro a intervenção. Incisões reduzidas quase sempre são acompanhadas por iluminação deficiente que não só dificultam a realização da técnica operatória, como contribuem para o aumento do tempo gasto na realização da operação ${ }^{(51)}$.

A equipe de cirurgiões, além de usar todos os meios disponíveis para prevenir complicações, deve preocupar-se com o tempo operatório. Em pacientes de idade avançada, as cirurgias com duração maior que duas horas acompanham-se de alta incidência de complicações, especialmente, respiratórias, renais e infecção da ferida. Cada hora adicional resulta em um acréscimo de $30 \%$ ou mais no índice de complicações pós-operatórias. Portanto, o cirurgião deve ter preparo técnico e emocional para realizar um ato operatório da melhor forma e no menor tempo possível. A fragilidade do idoso não permite que se perca tempo com indecisões, discussão, descontrole emocional e insegurança no ato operatório ${ }^{(1)}$.

Com essas considerações, no estudo de Haddawai et al. ${ }^{(29)}$ foi verificada uma relação significante entre a duração da cirurgia e as complicações pós-operatórias. Os autores referem que o grau de interferência nos diferentes órgãos e sistemas nas cirurgias longas é maior, em razão de uma perda considerável de sangue, hipoxia nos tecidos, hipotermia, desequilíbrio no balanço hidroelectrolítico, além das prováveis dificuldades respiratórias. 
A manipulação do tecido, a respiração por meio de aparelhos e as drogas anestésicas circulantes, constituem-se em fatores agressivos. Nesse sentido, executar o ato operatório, no menor tempo possível, favorece a diminuição de complicações na SRPA, sem que isto traga prejuízo à eficácia da técnica operatória ${ }^{(51)}$.

No intuito de abrandar a agressão ao paciente geriátrico pelo ato cirúrgico em si, a técnica operatória empregada deverá ser a menos agressiva possível, porém, suficiente para a solução ou alívio das afecções. Nesses pacientes, mesmo uma pequena perda de sangue é mal tolerada, não só pela hipovolemia, mas também pela diminuição de hemácias, responsáveis pelo transporte de oxigênio dos pulmões até as células e de gás carbônico no sentido inverso ${ }^{(51)}$.

No que se refere à síntese dos tecidos, atualmente utiliza-se, o bisturi elétrico que tem a finalidade de promover a eletrocoagulação, a eletrodissecção e a fulguração. Entretanto, seu uso incorreto poderá ocasionar choque elétrico (macrochoque), explosões, incêndios, causados pela combustão conseqüente do faíscamento gerado pelo contato do bisturi elétrico e substâncias inflamáveis utilizadas como anti-sépticos ou anestésicas. Além das queimaduras, no paciente, pode ocorrer parada cardíaca por micro ou macrochoque. O risco de queimadura está relacionado, sobretudo à colocação incorreta da placa dispersiva e instalações elétricas inadequadas ${ }^{(47)}$

Ainda com relação à síntese dos tecidos, deve-se também evitar o uso de materiais estranhos na ferida, além dos essencialmente necessários, como os fios de sutura que impedem o sangramento resultante de uma incisão ou corte. Ressaltando que a qualidade do fio usado em uma sutura evita reações alérgicas ${ }^{(47)}$. 
No que se refere ao paciente idoso, a cicatrização ocorrerá com maior dificuldade, implicando maior possibilidade de complicações decorrentes da síntese dos tecidos, inclusive, das anastomoses. Assim, as alterações circulatórias presentes em maior ou menor grau, em todos os órgãos, atuam como fatores agravantes desse problema $^{(5)}$.

Durante o ato anestésico-cirúrgico a monitorização deverá ser a mais completa possível, com medidas de oximetria, pressão arterial, temperatura e diurese. O controle volêmico é fundamental no paciente idoso, pois a hipovolemia pode gerar hipotensão arterial com baixo débito. Excessos volêmicos alteram pressões de enchimento do coração, podendo levar a um extravasamento de líquidos em cavidades que devem ser inspecionadas pelo cirurgião com o propósito de evitar o acúmulo de líquidos em cavidades. O monitoramento da diurese associado à diminuição dos espaços vazios decorrentes da manipulação cirúrgica é de extrema importância, uma vez que o idoso já possui diminuição da depuração renal e as alterações de volemia podem comprometer ainda mais a função dos rins ${ }^{(34)}$.

Outro sistema importante a ser monitorado em sala cirúrgica e de recuperação pós-anestésica é a termorregulação. A perda de calor é comum em todos os pacientes durante a anestesia geral, em razão dos anestésicos que alteram o centro de termorregulação no hipotálamo, inibem os tremores e produzem vasodilatação periférica, mais especificamente, os anestésicos voláteis afetam o centro de termorregulador hipotalâmico e também apresentam propriedades vasodilatadoras diretas. Já os opióides reduzem os mecanismos de conservação de calor pela vasoconstrição, influenciados por suas propriedades simpatocolíticas. Os barbitúricos contribuem para a diminuição da temperatura pela vasodilatação periférica que 
ocasionam, assim como os relaxantes musculares que reduzem o tônus muscular e inibem a produção de calor decorrente dos tremores. Não só a anestesia geral altera a termorregulação, a anestesia regional também produz bloqueio simpático, relaxamento muscular e bloqueio dos receptores térmicos, inibindo, assim, as respostas compensatórias ${ }^{(52)}$.

No paciente idoso, estes mecanismos são agravados pelas alterações decorrentes do envelhecimento, isto é, apresentam diminuição do metabolismo basal pela diminuição da massa muscular; deficiência do controle autonômico sobre os vasos cutâneos e diminuição do número desses vasos, prejudicando tanto a vasoconstrição como a vasodilatação; diminuição da intensidade dos calafrios e atrofia das glândulas sudoríparas. Portanto, o idoso mesmo acordado, é mais predisposto à hipotermia, aumentando o risco de não poder ter reserva suficiente para compensá-la ${ }^{(53)}$.

Diante dessa realidade e da vulnerabilidade em que se encontra o paciente idoso, frente ao procedimento anestésico cirúrgico, têm-se como objetivos: 


\section{Objetivos}




\section{OBJETIVOS}

- Identificar os fatores de risco de maior incidência no paciente cirúrgico idoso nos períodos pré e intra-operatórios.

- Identificar as complicações mais freqüentes no paciente cirúrgico idoso no período de recuperação pós-anestésica.

- Relacionar as complicações mais freqüentes do paciente cirúrgico idoso no período de recuperação pós-anestésica aos fatores de risco de maior incidência do paciente cirúrgico idoso nos períodos pré e intra-operatório. 
Material e Método 


\section{MATERIAL E MÉTODO}

\subsection{Tipo de estudo}

Trata-se de um estudo exploratório, descritivo, documental e retrospectivo com abordagem quantitativa.

\subsection{Local do estudo}

A coleta de dados foi realizada no Hospital Universitário da USP (HU-USP)

O HU-USP foi inaugurado em 1981, faz parte integrante do Sistema Integrado de Saúde da Universidade de São Paulo (SIUSP), tem como missão o ensino e a pesquisa, além de oferecer assistência multidisciplinar integral, de média complexidade, com base no perfil epidemiológico do Distrito de Saúde do Butantã. Apresenta como objetivos específicos: estimular e promover o ensino e a pesquisa oferece campo de atividade e desenvolvimento de alunos, desenvolve atividades assistenciais, de prevenção e tratamento de doenças, bem como de proteção e recuperação da saúde e colabora com as instituições de ensino no desenvolvimento de tecnologias assistenciais, educativas e operacionais expressas no Regimento do HU-USP.Constitui-se em campo de estágio das Faculdades de Medicina, Saúde Pública, Enfermagem, Farmácia e Odontologia.

Está localizado no campus da USP, na zona oeste da cidade de São Paulo. O HUUSP presta serviços ao corpo docente, discente e servidores da USP, bem como à população pertencente à região do Butantã (Núcleo I -DIR I) do Sistema Único de Saúde (SUS), atua como referência secundária regionalizada e integrada com os equipamentos de saúde da região. Com capacidade instalada de 408 leitos, distribuídos 
nas quatro especialidades básicas: médica, cirúrgica, obstetrícia e pediatria. Além do atendimento convencional, o hospital criou o Programa de Assistência Domiciliária (PAD).

Possui um serviço de atendimento ao usuário que tem por objetivo zelar pela qualidade do atendimento, funcionando como um canal de comunicação entre o usuário e o hospital.

O Centro Cirúrgico possui nove salas de cirurgia ativadas e sete leitos de recuperação pós-anestésica, mantém comunicação com as especialidades acima citadas, por meio de um agendamento cirúrgico diário que estabelece cirurgias programadas, extraprogramas e urgências.

A marcação de cirurgias programadas é feita por um sistema informatizado, no qual o cirurgião faz o agendamento da cirurgia no momento da consulta. No dia da cirurgia, o gerenciamento da programação cirúrgica fica sob a responsabilidade do enfermeiro do Centro Cirúrgico que modifica a seqüência das cirurgias programadas, quando necessário.

\subsection{Amostragem}

Durante o ano de 2004 foram realizadas 4380 cirurgias, 1169 em idosos e destas, 110 atendiam aos critérios de inclusão deste estudo, isto é: idosos de ambos sexos, submetidos a cirurgias eletivas, de emergência e urgência.

\subsection{Instrumento de coleta de dados}


Foi elaborado um instrumento Formulário 1 (anexo 2) contendo as seguintes seções :

Seção I. Aspectos relacionados à caracterização sócio-demográfica: idade, sexo, data de admissão ao hospital, data da cirurgia, estado civil, escolaridade.

Seção II. Aspectos relacionados ao paciente: Patologias associadas, hábitos, comportamento emocional na unidade, classificação do estado físico, segundo (ASA), pressão arterial.

Seção III. Aspectos relacionados ao período transoperatório: admissão no centro cirúrgico; nível de consciência, medicação pré-anestésico, sinais vitais.

Registro intra-operatório horário, diagnóstico, tipo de anestesia, equipamentos utilizados e posição cirúrgica.

Seção IV. Aspectos relacionados às complicações pós-operatórias imediatas em sala de recuperação pós-anestésica, referentes aos sistemas de termorregulação, cardiovascular, respiratório, urinário, e tegumentário.

\subsection{Procedimentos}

\subsubsection{Procedimento ético-legal}

A pesquisa foi encaminhada ao Comitê de Ética em Pesquisa do Hospital Universitário (HU) e considerada aprovada (registro CEP: 546/05).

\subsubsection{Procedimento de coleta de dados}


Após os trâmites legais da pesquisa, da solicitação e autorização à instituição, os dados foram coletados do prontuário do paciente, no Departamento de Estatística (SAME) do Hospital Universitário da Universidade de São Paulo (USP).

\subsubsection{Procedimento de análise dos dados}

Os dados foram armazenados no programa Microsoft Excel versão XP e processados no programa SPSS versão 13.

Dois tipos de análise foram usados: a análise descritiva, no qual foram registrados os valores de frequiência absoluta e relativa das variáveis sóciodemográficas e cirúrgicas, e regressão logística multivariada, ajustada por sexo e idade. 


\section{Resultados}




\section{RESULTADOS}

Tabela 1- Distribuição dos fatores de risco: sexo, idade, patologias de base, e a classificação do estado físico do paciente segundo, a ASA, relacionados ao paciente cirúrgico idoso no período pré-operatório. São Paulo, 2006.

\begin{tabular}{|c|c|c|}
\hline Fatores de risco & $\mathbf{n}^{\mathbf{0}}$ & $\%$ \\
\hline \multicolumn{3}{|l|}{ Sexo } \\
\hline Feminino & 48 & 43,6 \\
\hline Masculino & 62 & 56,4 \\
\hline Total & 110 & 100 \\
\hline \multicolumn{3}{|l|}{ Faixa etária } \\
\hline $60 \vdash 69$ & 31 & 28,2 \\
\hline $70 \vdash 79$ & 63 & 57,3 \\
\hline $80 \vdash 89$ & 13 & 11,8 \\
\hline$>90$ & 3 & 2,7 \\
\hline Total & 110 & 100 \\
\hline \multicolumn{3}{|l|}{ Patologias de base } \\
\hline Hipertensão arterial sistêmica (HAS) & 36 & 32,7 \\
\hline Diabetes & 10 & 9,1 \\
\hline HAS + Diabetes & 23 & 20,9 \\
\hline HAS + Artrite & 11 & 10 \\
\hline HAS + Doença pulmonar Obstrutiva & 10 & 9,1 \\
\hline HAS + Infecção trato urinário & 8 & 7,3 \\
\hline HAS + Tiroides & 5 & 4,5 \\
\hline Outros & 7 & 6,4 \\
\hline Total & 110 & 100 \\
\hline \multicolumn{3}{|l|}{ Estado físico segundo a ASA } \\
\hline I & 10 & 9,1 \\
\hline II & 66 & 60 \\
\hline III & 29 & 26,4 \\
\hline IV & 5 & 4,5 \\
\hline Total & 110 & 100 \\
\hline
\end{tabular}

Os dados da Tabela 1 mostram que, dos 110 pacientes idosos, a maioria $62(56,4 \%)$ era do sexo masculino; $63(57,3 \%)$ pacientes estavam na faixa etária de 70 a 79 anos; 36 (32,7\%) apresentavam hipertensão arterial sistêmica; 66 (60\%) foram classificados como ASA II. 
Tabela 2- Distribuição dos fatores de risco: tempo de cirurgia, posição cirúrgica, tipo de cirurgia, e tipo de anestesia relacionados ao paciente idoso no período intra-operatório. São Paulo, 2006.

\begin{tabular}{|c|c|c|}
\hline Fatores de risco & $n^{o}$ & $\%$ \\
\hline \multicolumn{3}{|l|}{ Tempo de Cirurgia } \\
\hline Inferior a 3 horas & 69 & 62,7 \\
\hline 3 a 5 horas & 33 & 30 \\
\hline Superior a 5 horas & 8 & 7,3 \\
\hline Total & 110 & 100 \\
\hline \multicolumn{3}{|l|}{ Posição cirúrgica em SO } \\
\hline Decúbito dorsal horizontal & 90 & 81,8 \\
\hline Litotômica & 10 & 9,1 \\
\hline Decúbito lateral direito & 7 & 6,4 \\
\hline Decúbito lateral esquerda & 3 & 2,7 \\
\hline Total & 110 & 100 \\
\hline \multicolumn{3}{|l|}{ Tipo de Cirurgia } \\
\hline Abdominal & 59 & 53,6 \\
\hline Artroplastia & 10 & 9,1 \\
\hline Redução de fratura & 10 & 9,1 \\
\hline Hernioplastia & 9 & 8,2 \\
\hline Prostatectomia & 7 & 6,4 \\
\hline Amputação & 7 & 6,4 \\
\hline Ressecção do trato urinário & 5 & 4,5 \\
\hline Lobectomia & 2 & 1,8 \\
\hline Hemorroidectomia & 1 & 0,9 \\
\hline Total & 110 & 100 \\
\hline \multicolumn{3}{|l|}{ Tipo de Anestesia } \\
\hline Geral & 56 & 50,9 \\
\hline Raquitidiana & 30 & 27,3 \\
\hline Peridural & 24 & 21,8 \\
\hline Total & 110 & 100 \\
\hline
\end{tabular}

Os dados da Tabela 2 mostram que, dos 110 prontuários da amostra, em 69 $(62,7 \%)$ os pacientes tiveram o tempo de cirurgia inferior a três horas; 90 pacientes $(81,8 \%)$ tiveram anotações referentes ao posicionamento em decúbito dorsal horizontal na mesa cirúrgica; $59(53,6 \%)$ tiveram referência de que os pacientes foram submetidos à cirurgia abdominal e $56(50,9 \%)$ referiram que os idosos foram submetidos à anestesia geral. 
Tabela 3- Distribuição das complicações mais freqüentes na sala de recuperação pós-anestésica relacionada ao paciente cirúrgico idoso. São Paulo, 2006.

\begin{tabular}{lcccc}
\hline $\begin{array}{l}\text { Complicações na sala de recu- } \\
\text { peração pós-anestésica }\end{array}$ & \multicolumn{2}{c}{ Sim } & \multicolumn{2}{c}{ Não } \\
\hline Hipotermia & 61 & 55,5 & 49 & 44,5 \\
Dor & 48 & 43,6 & 62 & 56,3 \\
Hipertensão arterial & 40 & 36,4 & 70 & 63,7 \\
Náusea e Vômito & 35 & 31,8 & 75 & 68,2 \\
Dispnéia & 22 & 20,0 & 88 & 80,0 \\
Outras complicações: & 12 & 10,9 & 98 & 89,1 \\
$\quad$ Taquicardia & 09 & 8,2 & 101 & 91,8 \\
$\quad$ Bradicardia & & & & \\
& & & & \\
\end{tabular}

Os dados da Tabela 3 mostram que, dos 110 prontuários analisados, 61 pontuavam que os pacientes $(55,5 \%)$ apresentaram hipotermia, $48(43,6 \%)$ dor e $40(36,4 \%)$ desenvolveram hipertensão arterial no período pós-operatório.

Dentre outras complicações cardiovasculares, os idosos apresentaram arritmias. Neste estudo, estas arritmias manifestaram-se como taquicardia em $12(10,9 \%)$ e bradicardia em $9(8,2 \%)$ idosos. 
Tabela 4 - Associação entre as complicações mais frequientes em sala de recuperação pós-anestésica e fatores de riscos relacionados ao paciente cirúrgico idoso no período pré-operatório. São Paulo, 2006.

\begin{tabular}{|c|c|c|c|c|c|c|c|c|c|c|c|c|c|c|}
\hline \multirow[b]{2}{*}{ Fatores de risco } & \multicolumn{2}{|c|}{ Hipotermia } & \multicolumn{2}{|c|}{ Dor } & \multicolumn{2}{|c|}{ Náusea Vômito } & \multicolumn{2}{|c|}{ HAS } & \multicolumn{2}{|c|}{ Dispnéia } & \multicolumn{2}{|c|}{ Taquicardia } & \multicolumn{2}{|c|}{ Bradicardia } \\
\hline & OR & $95 \%$ & OR & $95 \%$ & OR & $95 \%$ & OR & $95 \%$ & OR & $95 \%$ & OR & $95 \%$ & OR & $95 \%$ \\
\hline \multicolumn{15}{|l|}{$\overline{\operatorname{Sexo}}$} \\
\hline Feminino & 1 & - & 1 & - & 1 & - & 1 & - & 1 & - & 1 & - & 1 & - \\
\hline Masculino & 0,61 & $0,56-0,67$ & 0,64 & $0,57-0,69$ & 0,64 & $0,58-0,71$ & 1,27 & $1,15-1,40$ & 0,76 & $0,68-0,87$ & 1,71 & $1,46-1,99$ & 1,34 & $1,13-1,59$ \\
\hline \multicolumn{15}{|l|}{ Faixa etária } \\
\hline $60 \vdash 69$ & 1 & - & 1 & - & 1 & - & 1 & - & 1 & - & 1 & - & 1 & - \\
\hline $70 \vdash 79$ & 0,82 & $0,73-0,91$ & 1,04 & $0,93-1,15$ & 0,68 & $0,61-0,76$ & 0,78 & $0,70-0,87$ & 2,78 & $2,40-3,23$ & 0,69 & $0,58-0,81$ & 1,79 & $1,47-2,19$ \\
\hline $80 \vdash 89$ & 1,02 & $0,88-1,19$ & 0,84 & $0,72-0,99$ & 1,38 & $1,18-1,61$ & 0,64 & $0,55-0,75$ & 1,06 & $0,90-1,25$ & 1,40 & $1,13-1,74$ & 0,82 & $0,75-1,36$ \\
\hline$>90$ & 1,31 & $0,99-1,71$ & 0,32 & $0,22-1,35$ & 0,83 & $0,64-1,09$ & 0,26 & $0,10-1,46$ & 0,83 & $0,50-1,39$ & 1,31 & $0,99-1,71$ & 0,72 & $0,60-1,21$ \\
\hline \multicolumn{15}{|l|}{ HAS* } \\
\hline Normal & 1 & - & 1 & - & 1 & - & 1 & - & 1 & - & 1 & - & 1 & - \\
\hline Pré hipertensão & 0,48 & $0,42-0,55$ & 0,69 & $0,60-0,79$ & 2,46 & $2,14-2,83$ & 0,75 & $0,65-0,86$ & 0,85 & $0,72-0,99$ & 4,93 & $4,01-6,06$ & 3,43 & $2,56-4,57$ \\
\hline Estágio I & 0,89 & $0,79-0,99$ & 1,20 & $1,07-1,35$ & 0,66 & $0,58-0,75$ & 0,57 & $0,49-0,63$ & 0,88 & $0,76-10,1$ & 1,36 & $1,10-1,69$ & 1,69 & $1,27-2,26$ \\
\hline Estágio II & 0,37 & $0,32-0,45$ & 1,08 & $0,95-1,24$ & 0,95 & $0,82-1,09$ & 1,20 & $1,05-1,48$ & 0,70 & $0,59-0,83$ & 1,53 & $1,19-1,95$ & 8,01 & $6,12-10,49$ \\
\hline \multicolumn{15}{|l|}{$\mathbf{A S A}$} \\
\hline I & 1 & - & 1 & - & 1 & - & 1 & - & 1 & - & 1 & - & 1 & - \\
\hline II & - & - & 0,96 & $0,83-1,12$ & 0,94 & $0,22-4,04$ & 4,79 & $3,74-6,13$ & 1,27 & $1,04-1,54$ & 0,23 & $0,19-0,28$ & - & - \\
\hline III & - & - & 1,68 & $1,42-1,99$ & 1,23 & $0,26-5,81$ & 10,71 & $8,30-13,81$ & 0,54 & $0,43-0,68$ & 0,32 & $0,25-0,39$ & - & - \\
\hline IV & - & - & 3,80 & $2,83-5,10$ & 3,50 & $0,37-32,97$ & 0,94 & $0,88-1,34$ & 2,90 & $2,20-3,82$ & 0,66 & $0,48-0,89$ & - & - \\
\hline
\end{tabular}

* Hipertensão Arterial Sistêmica

$\mathrm{P}<0,05$

Ajustado por sexo e idade

Grupo de referência $=1$ 
Os dados da Tabela 4 mostram a associação entre as complicações mais freqüentes na recuperação pós-anestésica com os fatores de risco no período préoperatório. De acordo com os resultados da análise de regressão logística, o sexo masculino e feminino apresentaram associação estatisticamente significante com todas as complicações na sala recuperação pós-anestésica. Mas a possibilidade do sexo masculino apresentar complicações pós-operatórias na recuperação pós-anestésica, como: hipotermia $(\mathrm{OR}=0,61)$, dor $(\mathrm{OR}=0,64)$, náusea e vômito $(\mathrm{OR}=0,64)$ e, dispnéia $(\mathrm{OR}=0,76)$ foi menor, quando comparado com o sexo feminino. A possibilidade de apresentar hipertensão, taquicardia e bradicardia foi maior no sexo masculino, quando comparado ao sexo feminino $(\mathrm{OR}=1,27 ; 1,71 ; 1,34)$, respectivamente. Evidenciou-se, maior associação entre os idosos de 70 a 79 anos com a apresentação de dispnéia (OR= 2,78) e de idosos, numa faixa etária de 80 a 89 anos, apresentar taquicardia $(\mathrm{OR}=1,40)$. Não se obteve associação entre os idosos com idade acima de 90 anos com as complicações investigadas. Quanto à hipertensão arterial, o estágio II, obteve maior associação com bradicardia $(\mathrm{OR}=8,01)$, o escore ASA, as categorias II e III $(\mathrm{OR}=4,79$; 10,71) respectivamente, incrementam a possibilidade de apresentar hipertensão arterial no período de recuperação pós-anestésica. 
Tabela 5 - Associação entre as complicações mais freqüentes em sala de recuperação pós-anestésica e fatores de relacionados ao paciente cirúrgico idoso no período intra-operatório. São Paulo, 2006.

\begin{tabular}{|c|c|c|c|c|c|c|c|c|c|c|c|c|c|c|}
\hline \multirow[b]{2}{*}{ Fatores de risco } & \multicolumn{2}{|c|}{ Hipotermia } & \multicolumn{2}{|r|}{ Dor } & \multicolumn{2}{|c|}{ Náusea Vômito } & \multicolumn{2}{|c|}{ HAS* } & \multicolumn{2}{|c|}{ Dispnéia } & \multicolumn{2}{|c|}{ Taquicardia } & \multicolumn{2}{|c|}{ Bradicardia } \\
\hline & OR & $95 \%$ & $\mathrm{OR}$ & $95 \%$ & OR & $95 \%$ & OR & $95 \%$ & OR & $95 \%$ & $\mathrm{OR}$ & $95 \%$ & OR & $95 \%$ \\
\hline \multicolumn{15}{|l|}{ Tempo de cirurgia } \\
\hline Inferior a 3 & 1 & - & 1 & - & 1 & - & 1 & - & 1 & - & 1 & - & 1 & - \\
\hline 3 a 5 & 0,91 & $0,82-1,00$ & 2,34 & $2,12-2,61$ & 1,34 & $1,21-1,48$ & 0,53 & $0,49-0,60$ & 1,15 & $1,01-1,29$ & 0,52 & $0,43-0,63$ & 0,48 & $0,40-0,59$ \\
\hline Superior a 5 & 1,03 & $0,87-1,22$ & 2,28 & $1,92-2,72$ & 1,85 & $1,56-2,19$ & 6,49 & $5,32-7,92$ & 2,15 & $1,80-2,58$ & 3,94 & $3,25-4,78$ & 0,06 & $0,06-1,04$ \\
\hline \multicolumn{15}{|l|}{ Posição Cirúrgica } \\
\hline Decúbito dorsal horinzontal & 1 & - & 1 & - & 1 & - & 1 & - & 1 & - & 1 & - & 1 & - \\
\hline Decúbito lateral & 8,68 & $6,77-11,14$ & 3,12 & $2,58-3,77$ & 5,79 & $4,90-6,85$ & 0,52 & $0,45-0,61$ & 0,45 & $0,35-0,57$ & 1,11 & $0,86-1,43$ & 0,50 & $0,60-1,04$ \\
\hline Litotômica & 2,87 & $2,43-3,73$ & 0,99 & $0,85-1,14$ & 3,60 & $3,11-4,18$ & 0,36 & $0,31-0,41$ & 0,83 & $0,69-1,00$ & 1,91 & $1,57-2,33$ & 2,79 & $2,29-3,41$ \\
\hline \multicolumn{15}{|l|}{ Tipo de cirurgia } \\
\hline Outros & 1 & - & 1 & - & 1 & - & 1 & - & 1 & - & 1 & - & 1 & - \\
\hline Cavidade Abdominal & 0,89 & $0,81-0,99$ & 1,68 & $1,51-1,87$ & 1,20 & $1,06-1,34$ & 1,17 & $1,05-1,30$ & 1,56 & $1,37-1,79$ & 1,30 & $1,09-1,56$ & 1,60 & $1,31-1,94$ \\
\hline Artroplastia & 1,86 & $1,54-2,23$ & 1,42 & $1,20-1,71$ & 7,64 & $6,30-9,26$ & 0,60 & $0,49-0,74$ & 1,46 & $1,17-1,82$ & 1,26 & $0,94-1,70$ & 0,05 & $0,06-1,04$ \\
\hline Redução de fratura & 0,84 & $0,70-1,02$ & 2,05 & $1,69-2,49$ & 0,97 & $0,79-1,21$ & 1,61 & $1,33-1,39$ & 0,76 & $0,58-0,99$ & 3,71 & $2,91-4,74$ & 2,21 & $1,65-2,96$ \\
\hline \multicolumn{15}{|l|}{ Anestesia } \\
\hline Geral & 1 & - & 1 & - & 1 & - & 1 & - & 1 & - & 1 & - & 1 & - \\
\hline Peridural & 0,46 & $0,41-0,52$ & 0,53 & $0,47-0,60$ & 0,58 & $0,51-0,67$ & 0,23 & $0,20-0,26$ & 1,11 & $0,96-1,28$ & 3,82 & $3,15-4,63$ & 0,33 & $0,25-0,42$ \\
\hline Raquitidiana & 1,03 & $0,93-1,15$ & 0,61 & $0,54-0,68$ & 1,20 & $1,08-1,34$ & 0,25 & $0,22-0,29$ & 1,09 & $0,96-1,25$ & 4,24 & $3,52-5,09$ & 0,67 & $0,55-0,82$ \\
\hline
\end{tabular}

* Hipertensão Arterial Sistêmica 
Os dados da Tabela 5 mostram a associação entre as complicações mais freqüentes na recuperação pós-anestésica com os fatores de risco relacionados ao paciente cirúrgico idoso no período intra-operatório. De acordo com os resultados da análise de regressão logística, o tempo de cirurgia superior a cinco horas teve maior associação com hipertensão arterial $(\mathrm{OR}=6,49)$ quando comparado às cirurgias com duração entre 3 a 5 horas e inferior a 3 horas. A posição decúbito lateral apresentou maior associação com hipotermia, náusea, vômito e dor $(\mathrm{OR}=6,68 ; 5,79 ; 3,12)$, respectivamente, quando comparado às posições decúbito dorsal horizontal e litotômica.

Dentre os tipos de cirurgia, a artroplastia teve maior associação com náusea e vômito $(\mathrm{OR}=7,64)$ seguida de redução de fratura com taquicardia e dor $(\mathrm{OR}=3,71$ e 2,05), respectivamente. Quando realizada a associação entre o tipo de anestesia e complicações na recuperação pós-anestésica, a anestesia raquidiana apresentou maior associação com taquicardia $(\mathrm{OR}=4,24)$, quando comparada à anestesia geral e peridural. 


\section{Discussão}




\section{DISCUSSÃO}

5.1 Discussão dos resultados referentes aos fatores de risco relacionados ao paciente idoso cirúrgico no período pré-operatório.

$\mathrm{O}$ rápido crescimento populacional entre as pessoas maiores de 60 anos tem preocupado todos os setores, especialmente, os relacionados à área da saúde pública, isto porque doenças próprias do envelhecimento ganham maior expressão no conjunto da sociedade. Como resultado, encontra-se a demanda crescente por serviços de saúde, constituindo-se, estes em um dos desafios atuais frente à escassez de recursos para atender as necessidades da população idosa. Sendo assim, os serviços hospitalares são utilizados de maneira mais intensiva, as internações hospitalares são mais freqüentes e, conseqüentemente, o tempo de ocupação do leito é maior quando comparado a outras faixas etárias ${ }^{(54)}$.

No que refere ao sexo como fator de risco alguns tipos de cirurgias como as cirurgias ortopédicas se apresentam com predomínio no sexo feminino em razão das fraturas associadas à osteoporose, as cirurgias oncológicas também são realizadas com maior freqüência neste sexo, pela presença de câncer de útero e mama, próprios ao gênero feminino. Já, nas cirurgias urológicas a tendência de serem realizadas é no sexo masculino devido a doenças da próstata ${ }^{(55,119)}$

Alguns estudos mostram a incidência de complicações pós-operatórias relacionadas com o sexo. Assim, no estudo de Shahir et al. ${ }^{(58)}$, as complicações cardiológicas e respiratórias após cirurgia retal, foram duas vezes mais altas para o sexo feminino. 
Já, no estudo de Nguyen et al. ${ }^{(59)}$, mostra-se uma situação diferente. Pois nos idosos submetidos a cirurgias laparoscópicas, as complicações cardíacas, pulmonares e de sitio cirúrgico se apresentaram com maior freqüência no sexo masculino (11\%) quando comparado ao sexo feminino (9\%). Os autores o atribuem estes resultados à anatomia do corpo masculino (andróide), onde existe maior concentração de tecido adiposo, e consequientemente as cirurgias se tornam tecnicamente mais difíceis. Portanto, segundo os resultados, o alto índice de massa corpóreo (IMC) no homem influencia negativamente o período pós-operatório.

Por outra parte, Fontana refere que no período perioperatório, as alterações dos órgãos podem ser diferentes segundo o sexo, como por exemplo, o clareamento hepático é significativamente menor no sexo masculino. No estudo de Wong et al. ${ }^{(56)}$ o sexo masculino constituiu-se como fator de risco relacionado com o desenvolvimento de delírio após as cirurgias ortopédicas.

Enfocando a idade como outro fator de risco aqui apontado encontramos para 110 dos prontuários de idosos estudados uma maioria de 70 a 79 anos submetidos a procedimentos cirúrgicos. Estes dados foram similares aos encontrados em outros estudos $^{(57,58,59,60,61)}$. Portanto, embora sejam considerados pacientes de maior complexidade clínica, as cirurgias estão sendo realizadas com sucesso no paciente idoso, quando comparado com décadas passadas.

Com relação à presença de co-morbidades, neste estudo a hipertensão arterial sistêmica (HAS) apresentou-se em 58 pacientes idosos (52,8\%). Este resultado é superior aos encontrados por Leykin et al. ${ }^{(62)}$, no qual 1047 pacientes que conformaram a 
amostra, a média de idade foi de 61 a 80 anos, apresentando complicações cardíacas em $(15,3 \%)$, das quais a hipertensão arterial foi a mais importante $(5,65 \%)$.

A hipertensão arterial sistêmica afeta uma em cada quatro pessoas adultas nos Estados Unidos da América (EUA), e o mais importante, somente, um terço deles recebe tratamento adequado, enquanto o outro terço desconhece a presença da doença. Lorentz e Santos ${ }^{(63)}$. No Brasil, a hipertensão arterial constitui-se em um dos principais agravos à saúde da população e acomete com maior frequiência ao paciente idoso. A hipertensão arterial é considerada hoje como um problema de saúde pública, em razão dos elevados custos nas áreas médico-social em decorrência sobretudo das complicações, entre as quais se encontram a doença cérebrovascular, arterial coronariana, insuficiência cardíaca e renal $^{(64)}$.

O diagnóstico da hipertensão arterial no âmbito de Centro Cirúrgico é muito importante, sendo determinada pela mensuração da pressão arterial (PA). A VII Joint National Comitee $(\mathrm{JNC})^{(36)}$ classifica, como hipertensão os indivíduos com valores de pressão arterial acima de 140/90 mmHg, variando de estágio, conforme aumentam os valores de 20/10 mmhg. Entre seus componentes, isto é, pressão sistólica e diastólica ambos são importantes na monitorização da função cardiovascular no período perioperatório. Mas, recentemente, tem sido reconhecido que a hipertensão sistólica isolada é o subtipo mais comum em pessoas acima de 50 anos, sendo associada a riscos de doença coronariana e morte no idoso ${ }^{(65)}$.

A Sociedade Brasileira de Cardiologia sugere realizar, pelo menos, duas medidas de pressão arterial antes de determinar o diagnóstico de hipertensão. ${ }^{(64)}$ Num estudo realizado em pacientes submetidos a procedimentos cirúrgicos de menor porte, 
evidenciou-se variação das medidas de pressão arterial quando realizadas por diferentes profissionais. Assim, num primeiro momento foi mensurada pelo médico, sendo os valores médios de 22/14 $\mathrm{mm}$ hg e após 10 minutos, considerando este tempo como o período em que a PA retorna a seu estado normal, uma segunda avaliação mensurada, neste caso, pela enfermeira. Observou-se significante redução dos valores da PA quando comparados à primeira leitura. Os autores concluem que os valores da pressão arterial são influenciados pelo profissional de saúde que a verificou e denominam este fato de síndrome do avental branco ${ }^{(66)}$.

No período pré-operatório, se o paciente apresentar indícios de instalação da hipertensão arterial, este deverá ser avaliado e tratado prontamente com a finalidade de evitar complicações nos períodos intra-operatório e de recuperação pós-anestésica. Estas medidas exigem do profissional de saúde conhecimentos básicos do processo de envelhecimento $^{(65,67)}$.

De acordo com o que já foi citado, pode-se inferir que a forma de abordar o paciente no processo perioperatório torna-se fundamental, além de seguir as recomendações estabelecidas pela Sociedade Brasileira de Cardiologia ${ }^{(64)}$. Portanto, durante a avaliação do paciente cabe à enfermeira desenvolver estratégias para o estabelecimento de uma comunicação eficiente, evitando desencadear sentimentos de medo e ansiedade, os quais possivelmente repercutirão nos parâmetros dos sinais vitais. Nas variações dos parâmetros normais, inclui-se a elevação dos níveis da pressão arterial que poderá desencadear complicações, tanto no período intra-operatório como na sala de recuperação pós-anestésica. 
Com relação à condição física do paciente, esta pesquisa evidenciou que $60 \%$ foram classificados, segundo seu estado físico em ASA II e 26,4\% como ASA III. O resultado corrobora outros resultados ${ }^{(30,68,69)}$, nos quais, o estado físico dos pacientes apresentou uma variação entre os graus II e III. Os autores referem que à medida que se eleva o escore do estado físico do paciente, existe um aumento da possibilidade de apresentar complicações na sala recuperação pós-anestésica, às vezes, alcançando 23 a 42 vezes mais para pacientes classificados como ASA IV.

Outro estudo ${ }^{(57)}$ mostrou baixa porcentagem de pacientes com escore ASA maior que III em pacientes idosos submetidos à cirurgia abdominal. Nesta pesquisa, ressalta-se que os pacientes com quadros graves da doença foram compensados no período préoperatório.

Nos vários estudos, este escore vem sendo utilizado amplamente, tanto na prática clínica como na pesquisa ${ }^{(30,57,68,69)}$. Por outro lado, Leme; Carelli ${ }^{(70)}$ referem que o escore ASA apresenta grande variabilidade de interpretação, o que pode fazer com que sua análise subjetiva classifique o mesmo paciente ora em classe II, ora em classe III.

Embora considerado por alguns autores como subjetivo, o escore proposto pela ASA vem sendo utilizado ao longo do tempo por diversos pesquisadores, o que demonstra ser um instrumento que reflita verdadeiramente o conceito que deve medir, ou seja, o estado físico do paciente em face de cirurgia. Constituindo-se, dessa forma, em um escore confiável para seu uso. No entanto, existem outros instrumentos que produzem estimativas específicas relacionadas aos diferentes sistemas, que também são utilizados na avaliação do paciente. 
Entre esses, encontra-se a classificação do risco cardiológico perioperatório de Goldman et al. ${ }^{(71)}$; Detsky et al. ${ }^{(72)}$; Larsen et al. ${ }^{(73)}$. Ainda os autores referem que, em todo paciente idoso, é necessária a avaliação do estado mental por meio de testes simplificados. Com a abordagem de todos estes procedimentos, torna-se factível quantificar as possíveis alterações induzidas pelo ato anestésico e/ou cirúrgico.

Com relação ao posicionamento cirúrgico tem-se três posições básicas utilizadas em sala de operação, sendo estas, decúbito dorsal ou supina, decúbito ventral ou prona e lateral, as mesmas podem ser modificadas para atender as necessidades especificas dos pacientes ou a preferência dos cirurgiões $^{(74)}$.

Entretanto ocorrem mudanças fisiológicas nas diferentes posições no paciente saudável anestesiado, e ainda mais no paciente idoso, uma vez que os mecanismos compensatórios estão deprimidos pelos agentes farmacológicos e processos fisiopatológicos, tornando-o fragilizado e incapacitado de compensar prontamente às mudanças posturais abruptas. Portanto, na posição em decúbito dorsal e litotômica, pode-se apresentar hipoxia, devido ao incremento da pressão intraabdominal contra o diafragma diminuindo conseqüentemente a capacidade residual funcional respiratória. Já na posição em decúbito lateral, além do comprometimento da função respiratória, pode se apresentar instabilidade hemodinâmica ${ }^{(74)}$.

Assim, Widam; Isacson ${ }^{(75)}$ em seu estudo comparou as vantagens e desvantagens da posição lateral e posição supina em pacientes idosos submetidos a cirurgias ortopédicas de quadril. Nos seus resultados mostraram uma pequena $(210 \mathrm{ml})$, mas significante diminuição de perda sangüínea na posição lateral quando comparado com a posição supina. A razão deste fenômeno não é claro, mas os autores acreditam que seja 
pelo fato de estar o campo operatório mais elevado em relação ao coração, o que reduz conseqüentemente o fluxo arterial e venoso.

Já, Hwang et al. ${ }^{(76)}$ descreve como outro tipo de alteração decorrente do posicionamento cirúrgico, o aumento da pressão intraocular (PIO), complicação rara, mas séria, podendo em alguns casos ocasionar perda visual no período pós-operatório. Sendo assim, o autor pesquisou em pacientes submetidos a cirurgias de pulmão as alterações de pressão intraocular após a mudança da posição cirúrgica, de supina para lateral. Os resultados mostraram que a PIO aumenta na posição lateral, o que o atribuem ao aumento do volume vascular coloidal e pressão venosa episcleral, mecanismos que são influenciados a vezes por efeitos das drogas anestésicas.

Com relação ao tempo de cirurgia, anteriormente esta variava de 3 a 6 horas em procedimentos cirúrgicos comuns, hoje, graças à evolução das técnicas pouco agressivas, equipamentos cirúrgicos, assim como a habilidade do cirurgião, a média deste tempo vem diminuindo ${ }^{(77)}$.

Ruedy ; Murphy ${ }^{(78)}$ referem que um menor tempo operatório contribui para baixos índices de complicações pós-operatórias, para uma mínima hemorragia no ato cirúrgico, bem como para um curto período de internação. Estes fatores influenciarão positivamente na recuperação e reabilitação do paciente idoso, desde que respeite o equilíbrio e a correção dos problemas clínicos existentes.

Assim, no estudo de Macedo et al. ${ }^{(79)}$ um dos parâmetros avaliados foi o tempo cirúrgico em pacientes submetidos a artroplastia de quadril, através de duas abordagens, por via ântero-lateral e por via posterior. Os resultados mostraram que os pacientes operados por abordagem pela via posterior apresentaram redução do tempo cirúrgico, do 
sangramento intra-operatório e do tempo de internação pós-operatória, quando comparados aos pacientes operados pela via ântero-lateral. Os autores concluem que o tempo cirúrgico diminuiu no primeiro caso devido à boa exposição das estruturas osteomusculares.

Com relação ao tipo de cirurgia, as cirurgias abdominais foram as mais frequientes no paciente idoso, dentre as quais se encontram as colecistectomias, coledocotomias, gastrectomias, colectomias, esplenectomias e hepatotectomias.

Embora outros tipos de cirurgias, como as cardíacas, as torácicas ou as ortopédicas sejam realizadas freqüentemente no paciente idoso, as abdominais de grande porte estão aumentando a cada ano e sua incidência está relacionada diretamente com o avançar da idade, apresentando uma prevalência global de 36,8\% e com distribuição em $\operatorname{ambos} \operatorname{sexos}^{(80,81,82)}$.

Koyima; Narita ${ }^{(57)}$ concluíram que o sexo masculino e a cirurgia abdominal constituem fatores de risco, pela possibilidade desse tipo de cirurgia causar grandes alterações hidroeletrolíticas, de temperatura e depressão ventilatória, elevando o risco do paciente apresentar complicações hemodinâmicas e pulmonares no período de recuperação pós-anestésica.

Pessaux et al. ${ }^{(60)}$ estudaram dois grupos de idosos (menores de 75 anos e maiores de 75 anos) submetidos a cirurgias minimamente invasivas. Obtiveram como resultados que o grupo de idosos maiores de 75 anos apresentou mais complicações quando comparado ao grupo de menores de 75 anos e dentre elas os processos infecciosos da ferida operatória foram os mais comuns. Concluíram-se que a cirurgia minimamente invasiva constitui uma vantagem para o grupo de idosos menores de 75 anos. 
Entretanto, em sua pesquisa Nguyen et al. ${ }^{(59)}$ identificaram três fatores associados à presença de resultados adversos no período pós-operatório em cirurgias laparoscópicas, que foram: idade maior que 60 anos, gênero masculino e a experiência do cirurgião. Dos três fatores, a experiência do cirurgião influenciou negativamente no tempo da cirurgia, na conversão da cirurgia para laparatomia e no maior índice de complicações pós-operatórias. Os autores concluíram que, a incorporação de novas técnicas na prática clínica está freqüentemente associada a uma curva do aprendizado, ou seja, quanto mais procedimentos cirúrgicos o cirurgião realizar, maior habilidade será adquirida para futuras cirurgias.

Outro fator que poderá influenciar nas complicações na recuperação pósanestésica, é o retardo de diagnóstico e, conseqüentemente, a urgência das cirurgias. De modo geral, o indivíduo idoso tem sintomas pouco perceptíveis, de intensidade menor e inespecíficos. Estes, muitas vezes, são subvalorizados pelo idoso, família e equipe de saúde, podendo, em algumas situações, atribuir-se erroneamente às características próprias do envelhecimento e considerando-se somente quando os sintomas forem mantidos por longos períodos de tempo ${ }^{(83)}$.

No diagnóstico, este retardo torna freqüente a presença de quadros de agudização e formas complicadas da doença em fase avançada, constituindo-se as cirurgias de urgência, como único tratamento alternativo ao idoso. $\mathrm{O}$ que pode ser evidenciado nas altas porcentagens de cirurgias de urgência e, conseqüentemente nos índices de morbidade e mortalidade perioperatória, quando comparadas às cirurgias eletivas ${ }^{(68)}$.

Por outro lado, Tan et al. ${ }^{(84)}$ referem que, quando a doença é diagnosticada precocemente, existem algumas situações em que há resistência por parte do idoso ao 
tratamento cirúrgico, em razão do temor do que virá acontecer no futuro. Nesse contexto, Heriot et al. ${ }^{(85)}$, apontam os casos em que o diagnóstico não é favorável e o procedimento cirúrgico é a única opção. O paciente deverá tomar a decisão de fazer ou não a cirurgia, cabendo ao cirurgião informar sobre as estimativas do risco, tanto ao paciente como à família.

De acordo com o assinalado anteriormente, em razão da demanda dos idosos aos serviços de saúde, quadros graves de doenças podem ser corrigidos a tempo, visto que surgem métodos mais avançados para diagnóstico. Hoje, não se identifica um problema de saúde com base só nos dados clínicos, os aparelhos sofisticados fazem isso com precisão e em menos tempo. É necessário ressaltar que estes recursos assim como os profissionais especializados estão centralizados em hospitais e instituições de grande porte.

No entanto, nos estabelecimentos de saúde de I nível de atenção, a história clínica bem obtida e o exame físico no consultório ainda continuam sendo o meio de diagnóstico para as doenças.

Com relação ao tipo de anestesia, a geral, foi a mais realizada nos idosos, o que corrobora os achados de outros estudos ${ }^{(29,35,59,60,61)}$. Este resultado tem como justificativa os benefícios da anestesia geral quando comparada a outras técnicas anestésicas no idoso, como, por exemplo, a anestesia regional. Nesta, torna-se difícil localizar o espaço epidural ou subaracnóideo em conseqüência da deformidade espinhal freqüente nos $\operatorname{idosos}^{(86)}$.

Mesmo assim, existem controvérsias quanto à utilização do tipo de anestesia; evidências mostram notáveis benefícios para o idoso, quando for utilizada a anestesia 
regional, entre as quais se pode citar: preservação da perfusão e metabolismo orgânico, atenuação da influência do anestésico sobre o sistema imunitário, anestesia segmentar e baixa dose do anestésico. Com relação ao período pós-operatório, pode-se mencionar a redução dos índices de mortalidade e complicações como, as respiratórias, trombose venosa profunda, baixa incidência de hipotensão e isquemia de miocárdio, reabilitação e, conseqüentemente, a alta precoce.

Koyima; Narita ${ }^{(57)}$ referem que a anestesia regional é utilizada em procedimentos ambulatoriais e ortopédicos menores. Já a anestesia geral deveria ser usada em cirurgias de grande porte, como as abdominais, Portanto, os pesquisadores concluem que a anestesia também deve ser determinada pelo tipo de cirurgia e não apenas pelo estado do paciente.

Diante destas considerações, o tipo de anestesia deve ser adaptado às alterações anatômicas e funcionais de órgãos e sistemas do idoso, farmacocinética e farmacodinâmica dos agentes anestésicos, bem como nas características clínicas do paciente e do procedimento cirúrgico. Portanto, lidar com a população idosa, no contexto anestésico-cirúrgico, constitui-se, em um desafio aos anestesiologistas e à equipe de enfermagem, que devem providenciar as medidas necessárias para o sucesso da cirurgia e bem-estar do paciente.

5.2 Discussão dos resultados referentes às complicações mais freqüentes na recuperação pós-anestésica. 


\section{HIPOTERMIA}

Pelos dados da Tabela 3, verifica-se que hipotermia foi a complicação com maior freqüência $(55,5 \%)$ na recuperação pós-anestésica. Estes dados são condizentes com o estudo de Frank et al. ${ }^{(87)}$ quando assinalam que pacientes maiores de 55 anos têm o risco aumentado de hipotermia, após as cirurgias.

A manutenção da temperatura corporal durante o ato anestésico-cirúrgico e na recuperação pós-anestésica é importante visto que a presença de alterações da temperatura, como a hipotermia está associada a numerosas complicações. O que pode ser evidenciado no estudo de Holm $^{(88)}$ quando se avaliou o efeito da hipotermia sobre o consumo de oxigênio durante a permanência na sala de recuperação pós-anestésica em indivíduos de diferentes faixas etárias. Mensuraram o consumo de $\mathrm{O}_{2}$ e ventilação por minuto. Os resultados mostraram que, a perda da temperatura de $0,2^{\circ} \mathrm{C}$, produzia um pequeno incremento no consumo de oxigênio de $7 \%$, enquanto os indivíduos com perda da temperatura maior a $0,3^{\circ} \mathrm{C}$ experimentaram um incremento no consumo de oxigênio de até $40 \%$.

Após o fim do ato anestésico, é diminuída a concentração de anestésicos no sistema nervoso central (SNC), e o organismo retorna às respostas de termorregulação. A temperatura corporal tende a voltar ao normal em um período de 2 a 5 horas, mas, os fármacos residuais e o uso de opióides para tratamento da dor pós-operatória diminuem a eficácia dessas respostas que, somados à idade do paciente, acabam influenciando a queda da temperatura corporal ${ }^{(89)}$.

No estudo de Frank et al. ${ }^{(87)}$, a hipotermia esta associada aos eventos cardíacos no período de recuperação pós-anestésica. Já em um outro estudo, em que se realizou uma 
metanálise, o pesquisador identificou que, no grupo de pacientes hipotérmicos realizaram-se com maior freqüência procedimentos como transfusões de células vermelhas, plasma e plaquetas. Além disso, foram observados infecção do sitio cirúrgico, diminuição no metabolismo das drogas, aumento da necessidade de mecanismos de ventilação e maior incidência de morbidade relacionada ao sistema cardiovascular $^{(90)}$.

No paciente idoso cirúrgico, a resposta de termorregulação está afetada pela idade e medicações, incluindo, os anestésicos; a resposta de vasoconstricção está abolida, precisando-se de temperaturas extremas para ativá-la. Esta resposta é agravada no paciente idoso pela presença de co-morbidades, temperatura do ambiente e técnica cirúrgica onde existe maior exposição de vísceras quanto maior for o tempo operatório, incrementando, dessa forma, a probabilidade de exacerbar as complicações no período pós-operatório $^{(91)}$.

Assim, é necessário saber que, a temperatura geralmente, diminui $1^{\circ} \mathrm{C}$ nos primeiros 40 minutos após a indução anestésica em razão da vasodilatação periférica e redistribuição interna de calor $^{(92)}$. Considerando isso, todo paciente submetido a procedimento com mais de 30 minutos de duração deve ter sua temperatura monitorizada e mantida ao redor de $36{ }^{\circ} \mathrm{C}$, a não ser que a hipotermia esteja especificamente indicada. Pacientes submetidos a intervenções cirúrgicas de grande porte sob anestesia regional também devem ter sua temperatura monitorizada ${ }^{(87)}$.

Biazzoto et al. ${ }^{(93)}$ referem que, apesar da manutenção da normotermia no período perioperatório ser um objetivo reconhecido, a hipotermia ocorre com freqüência durante o ato anestésico-cirúrgico por diversos mecanismos. Sua instalação expõe o paciente ao 
triplo de incidências de eventos adversos como os cardíacos, hemorragias e infecções na área cirúrgica; além de prolongar o tempo de permanência hospitalar.

Diante do exposto, com a monitorização da temperatura do paciente em sala de cirurgia e sala de recuperação pós-anestésica em intervalos regulares, será permitido detectar precocemente a hipotermia, podendo dessa forma, minimizar a incidência de eventos adversos no período de recuperação pós-anestésica, por meio de medidas que promovam a manutenção da temperatura do paciente associada à temperatura do ambiente.

\section{DOR PÓS-OPERATÓRIA}

A dor ocupou o segundo lugar dentro das complicações apresentadas pelos idosos com uma porcentagem de 43,6\%, A dor, também apresentou-se como uma das complicações freqüentes na recuperação pós-anestésica nos estudos de Garavello ${ }^{(94)}$; Leardi et al. ${ }^{(95)}$. Em ambos os estudos foram avaliados cem pacientes submetidos à hernioplastia. Os resultados mostraram que a complicação mais freqüente apresentada pelos pacientes na recuperação pós-anestésica foi a dor, com (86\%) para o primeiro estudo e, (13\%), para o segundo estudo.

Entre outros estudos que fazem referência à presença de dor no período pósoperatório, na sua maioria, estão focados para comprovar a eficácia de certos fármacos, técnicas anestésicas e outros tratamentos complementares.

Em seu estudo com pacientes submetidos a cirurgias abdominais de grande porte,

Shapiro et al. ${ }^{(96)}$, compararam três técnicas analgésicas para o tratamento da dor pósoperatória aguda, sendo estas: por via oral com diclofenaco considerado dentro do grupo 
dos antiinflamatórios não esteróides (NAIDs), analgesia intravenosa controlada à base de morfina e analgesia intratecal ou peridural também a base de morfina. Em seus resultados, as três técnicas provêem efetiva analgesia, porém, com a presença de efeitos adversos como: bradicardia e prurido no grupo que recebeu morfina por via peridural a frequiência de náusea e vômito foram similares nos três grupos. Os autores enfatizam que, não somente deve ser avaliada a percepção da dor subjetiva, mas também a incidência de efeitos adversos indesejáveis. Portanto, concluem que, quando analisados todos os aspectos associados ao tratamento para a dor, a técnica analgésica em base à antiinflamatórios não esteróides constitui uma alternativa para analgesia intravenosa controlada e morfina por via peridural.

Em seu estudo, Parker et al. ${ }^{(35)}$ assinalam que, a analgesia peridural controlada pelo paciente é o tratamento com menores ocorrências de eventos adversos cardíacos. Dessa forma, Chaves; Pimenta ${ }^{(97)}$ compararam cinco métodos de analgesia pósoperatória no tratamento da dor, alívio, efeitos colaterais, custo e consumo de analgésicos nesse período. Os resultados mostraram diferenças estatisticamente significantes entre os métodos, assim como nos escores da dor, ocorrência de efeitos colaterais e custo. Os autores referiram que estes fatores devem ser considerados no momento da escolha do método analgésico.

A presença de dor, além de causar alterações fisiológicas, provoca transtornos de humor no paciente idoso. Assim, Chung; Lui ${ }^{(98)}$ estudaram a intensidade da dor vivenciada e sua satisfação com seu manejo na recuperação pós-anestésica. Os resultados mostram que, aproximadamente, $85 \%$ queixavam-se de dor nas primeiras 24 
horas, dos quais $48,6 \%$ concordaram que tanto o enfermeiro como o médico não davam importância ao alívio da dor.

No tratamento deste sintoma para o paciente idoso, Parker et al. ${ }^{(35)}$ referem que se deve ter precaução para não mascarar outros sintomas considerados como "silenciosos" com graves consequiências, como o infarto do miocárdio, que se podem apresentar nesse período.

No entanto, o tratamento da dor no período pós-operatório representa um dilema para os anestesiologistas. Por exemplo, os tratamentos à base de opióides têm excelentes propriedades analgésicas, mas, isso resulta no risco de apresentar efeitos adversos, os quais são mais acentuados no paciente idoso. Embora os analgésicos não esteróides tornem-se uma alternativa para o uso dos opióides, corre-se o risco de apresentar irritação gastrointestinal, sangramento, dano da função renal e distúrbios na coagulação sangüínea.

Atualmente existe uma variedade de tratamento farmacológico para a dor no período pós-operatório, apesar disso a dor continua sendo uma das complicações que requer observação e cuidados especiais na sala de recuperação pós-anestésica (SRPA). $\mathrm{Na}$ tentativa de achar o melhor tratamento, diversos estudos têm focado seu objetivo neste tema. Embora alguns fármacos utilizados de forma isolada ou combinados a técnicas sejam efetivos no controle da dor, nenhum deles apresenta-se como um tratamento ideal para a população idosa, em razão dos efeitos adversos que provocam, os quais são exacerbados quando estão presentes alterações na estrutura e decréscimo na função de tecidos e órgãos, como é o caso dos idosos. 
Diante da diversidade de artigos que abordam a dor, pode-se inferir que existem várias formas de lidar com a mesma na recuperação pós-anestésica. Portanto, o desafio, da escolha do tratamento adequado cabe aos anestesiologistas e ao enfermeiro da sala de recuperação pós-anestésica, cabe providenciar o tratamento, avaliação, prevenção e medidas de monitoramento e alívio de quadros álgicos durante esse período.

\section{HIPERTENSÃO ARTERIAL}

Outra complicação identificada na sala de recuperação pós-anestésica, registrada em 40 pacientes $(36,4 \%)$, foi a hipertensão arterial sistêmica. A presença desta complicação cardiovascular pode ser atribuída ao número de pacientes com hipertensão arterial sistêmica já no período pré-operatório 58 (52,8\%) (Tabela 2).

Se foram verificados os dados da Tabela 1, pode-se observar, que dos 58 pacientes que apresentaram hipertensão arterial sistêmica (HAS) no período pré-operatório, 18 deles mostraram redução da pressão arterial, por medidas de controle arterial restando ainda 40 pacientes com a presença de hipertensão arterial.

A ocorrência de hipertensão arterial sistêmica no período pós-operatório tem sido focada por vários autores. Assim, Maggio et al. ${ }^{(99)}$ referem que cerca de $1,4 \%$ de todos os pacientes admitidos para um procedimento cirúrgico, recebem medicação antihipertensiva. Por outro lado, Lorentz; Santos ${ }^{(63)}$ mencionam que, a porcentagem dos pacientes hipertensos que se submetem a cirurgias, varia de acordo com o tipo de cirurgia.

A presença de hipertensão arterial constitui-se em um fator predisponente à aparição de complicações cardíacas maiores como, por exemplo, o infarto do miocárdio. 
Esta associação foi evidenciada no estudo de meta-análise realizada por Foëx; Sear ${ }^{(100)}$ durante o período de 1978 a 2002, tendo como base 30 trabalhos e envolvendo 13.666 pacientes. Os resultados foram avaliados em termos de complicações cardiovasculares, no qual o infarto de miocárdio apresentou um índice de (OR 1,31), embora esta associação seja pequena, deverá ser interpretada com precaução, especialmente em populações idosas.

No estudo de Parker et al. ${ }^{(35)}$ a hipertensão arterial está associada à apresentação de eventos cardíacos e danos da função renal. Além disso, a probabilidade de surgir variações da pressão sangüínea durante o período transoperatório está aumentada, em razão da diminuição do volume intravascular e da sensibilidade dos reflexos barorreceptores. $\mathrm{O}$ autor refere que, em pacientes hipertensos, o tratamento medicamentoso pode ser mantido no decorrer da cirurgia.

Ainda com relação à presença da hipertensão como fator predisponente na aparição de complicações pós-operatórias, Araújo et al. ${ }^{(101)}$ realizaram um estudo retrospectivo em prontuários de pacientes em dois períodos de 1989-1992 grupo 1 (G1) e de 1999-2002 grupo 2 (G2). Em seus resultados, observaram maior incidência de efeitos adversos no (G1) (15,7\%) sendo, a dor e hipertensão arterial os mais freqüentes. O tempo médio de permanência não diferiu entre os grupos (tempo maior a 200 minutos). Os autores atribuem estes resultados à falta de equipamentos para monitoramento dos pacientes, assim como às técnicas anestésicas e drogas utilizadas nessa época.

Como outro fator que contribui na apresentação de hipertensão arterial e intensifica a atividade do sistema nervoso central, pode-se citar a ansiedade, presente no 
período perioperatório, uma vez que estimula o sistema simpático com ação direta sobre a medula supra-renal, liberando conseqüentemente as catecolaminas (adrenalina e noradrenalina). A presença destas sustâncias na corrente sangüínea provoca alterações, como aumento da pressão arterial, taquicardia, entre outras ${ }^{(91)}$.

Durante o processo anestésico cirúrgico, é necessário considerar que o paciente idoso apresenta maior risco de flutuação da pressão sangüínea, ou seja, diminuição da PA e da frequiência cardíaca na indução anestésica, incrementando-se na intubação e, posterior estabilização durante a cirurgia. No final do procedimento novamente se elevam o índice cardíaco e a pressão arterial durante a extubação até o despertar. No paciente hipertenso, estas variações podem ocasionar a presença de arritmias e outras complicações como, isquemia do miocárdio, isquemia cerebral e infarto do miocárdio.

Lorentz; Santos ${ }^{(63)}$ assinalam que, na atualidade com a evolução da técnica anestésica, o avanço na indústria farmacêutica, o monitoramento contínuo da anestesia e o tratamento imediato de possíveis intercorrências tem-se tem um melhor controle da pressão arterial do paciente hipertenso, favorecendo, dessa forma, a diminuição dos eventos adversos quando comparados às décadas passadas.

Seguindo a classificação da hipertensão arterial sistêmica, os estágios I e II estão presentes na maioria da população idosa, explicação que foi adotada pelos pesquisadores quando identificaram que não existe associação entre hipertensão arterial no momento da admissão ao Centro Cirúrgico com os eventos cardíacos no período de recuperação pós-anestésica. Para eles, existe maior probabilidade de apresentar estes eventos nos pacientes com hipertensão no estágio III ${ }^{(100)}$. 
Ainda, continuando os autores supracitados ressaltam que, no caso da hipertensão arterial sistólica ser o único fator de risco associado ao paciente idoso, pode-se dar continuidade ao procedimento cirúrgico, já que existem métodos não invasivos que garantem melhor controle do paciente, mediante o monitoramento da pressão arterial no procedimento cirúrgico ${ }^{(66)}$.

Nesse sentido, diante da presença da hipertensão arterial sistólica no contexto cirúrgico, torna-se fundamental a avaliação clínica do paciente idoso com a finalidade de identificar outros fatores cardiovasculares, diagnosticar doenças associadas à etiologia da hipertensão confirmar níveis elevados de pressão arterial. Por outro lado, conhecendo que a natureza da hipertensão arterial sistólica é multifatorial, sua orientação estará voltada a vários focos podendo requerer o apoio de outros profissionais, além do médico $^{(64)}$.

Pelos estudos supracitados, embora alguns resultados não mostrem a associação entre hipertensão arterial e complicações pós-operatórias no paciente idoso, a presença destas eventualidades independente de qualquer estágio deverá ser manejada e controlada durante o período perioperatório, pois está constatado que o idoso tem limitações funcionais para responder às alterações hemodinâmicas por mínimas que estas sejam.

Por outra parte, é necessário considerar que alguns estudos mostram índices de complicações maiores, como o infarto do miocárdio, mas, não especificamente, a presença de sinais e sintomas que advertem a instalação de alguma alteração que se não for identificada e controlada em um tempo hábil posteriormente poderá progredir a complicações maiores. 


\section{Náusea e vômitos}

Neste estudo, a presença de náuseas e vômitos foi registrada em 31,8\% no período de recuperação anestésica.

Estes sintomas são definidos como sensações desagradáveis no período de recuperação pós-anestésica. O conceito foi confirmado no estudo de Eberhart et al. ${ }^{(102)}$ quando avaliaram 220 pacientes e estratificaram, quais dos eventos desejariam evitar na unidade de recuperação pós-anestésica. A náusea e o vômito foram as situações que o maior número de pacientes desejaria evitar (49\%), seguidos pela dor (27\%) e ausência de sedação (13\%). Os autores reportaram que os pacientes estariam dispostos a aceitar custos adicionais para atenuar ou prevenir estas manifestações.

A náusea e o vômito constituem-se em uma das complicações de maior incidência na sala de recuperação pós-anestésica. Em 1960, quando se utilizavam agentes, como o éter, era freqüente sua incidência em $60 \%$ dos pacientes. Atualmente, apesar dos novos agentes anestésicos e antieméticos, as náuseas e vômitos persistem em $20 \%$ a $30 \%$ nos pacientes $^{(103)}$.

Embora sua etiologia não seja completamente definida, sabe-se que tem caráter multifatorial. Entre os fatores associados que podem aumentar sua aparição estão aqueles relacionados ao paciente como, por exemplo, sexo feminino, idade (acima de 60 anos), ansiedade, história prévia de náuseas, vômitos e os relacionados com a cirurgia e técnica anestésica ${ }^{(103,104)}$. 
A presença destes sintomas desagradáveis pode retardar a transferência dos pacientes pós-operados para a clínica de origem, afetando dessa forma, o fluxo de cirurgias e, conseqüentemente, gerando um impacto significativo no aspecto econômico para os hospitais. Nos países desenvolvidos, a presença de náuseas e vômitos em pacientes tem levado à introdução de guias e protocolos para seu melhor manejo, diminuindo significativamente a porcentagem desta complicação no período de recuperação anestésica ${ }^{(105)}$.

Nesse sentido, no estudo de Eberharth et al. ${ }^{(102)}$ foi utilizado um protocolo relacionado com a anestesia (técnica e agentes anestésicos) na tentativa de diminuir as náuseas e os vômitos no período de recuperação pós-anestésica. Foram 760 pacientes idosos submetidos a cirurgias de grande porte e em sua maioria (97\%) sob anestesia geral. Entre seus resultados, somente 22 pacientes $(2,9 \%)$ desenvolveram os sintomas, desses 21 (95\%) tinham fatores associados, entre os quais se encontram o sexo feminino, cirurgia ginecológica, cirurgia abdominal e falta de medicação antiemética.

À luz da indústria farmacêutica, existem numerosos enfoques fármacoterapêuticos para o tratamento destes sintomas. Assim, Abreu ${ }^{(106)}$ em seu estudo comparou a eficácia de quatro diferentes fármacos utilizados como tratamento profilático, entre estes: ondansetron, metoclopramida, droperidol, dexametasona e o grupo controle. As pacientes foram submetidas a cirurgia ginecológica por via laparoscópica, sob anestesia geral. Entre seus resultados, o ondansetron mostrou-se, como a droga eficaz na prevenção de náusea (incidência 4,5\%) e de vômito $(5,26 \%$ ) no período de recuperação pós-anestésica, seguida da metoclopramida e dexametasona, que nesta ordem foram as menos eficazes. 
Já para Twersky ${ }^{(104)}$, a metoclopramida, droperidol, embora efetivas possuem efeitos colaterais. Drogas como ondansetron e dolasetron provêem um bom direcionamento das náuseas e vômitos, agindo no bloqueio dos receptores centrais e periféricos que modulam o reflexo do vômito.

Os parágrafos supracitados sugerem o tratamento farmacológico para esses sintomas, mas advertem a presença de efeitos adversos. Para modificar esse quadro, Anderson; Gross ${ }^{(107)}$ propõem um tratamento complementar e alternativo (aromaterapia com álcool ou peppermint) para náuseas e vômitos na recuperação pós-anestésica. Foram 33 pacientes, nos quais a gravidade da náusea e vômito foi mensurada por meio da escala visual analógica (EVA). Os autores concluem que aromaterapia reduz a percepção subjetiva das náuseas, diminuindo, dessa forma, o uso de antieméticos intravenosos em 50\%. Os autores enfatizam que este tipo de tratamento já é utilizado em clínicas cirúrgicas, tem baixo custo e não apresentam efeitos adversos. Sendo assim, surge a utilização desse tratamento alternativo para pacientes pós-operados na recuperação pós-anestésica.

Hoje, apesar dos diferentes tipos de tratamento, ainda estes sintomas estão presentes nos pacientes em sala de cirurgia ou na sala de recuperação pós-anestésica. $\mathrm{O}$ que demanda a criação de mecanismos que garantam a diminuição de náuseas e vômitos, sejam as terapias convencionais ou buscando novos recursos que visem a melhorar o conforto do paciente. Um dos cuidados já citados é a utilização da Terapia Complementar como um novo recurso. Na cidade de São Paulo, as enfermeiras já possuem uma legislação que regulamenta o uso da Terapia Complementar, a Lei é a $\mathrm{N}^{\circ}$ 13.717, de 8 de janeiro de 2004, dentre elas, a aromaterapia, a reflexologia, as essências 
florais, e com isso a Enfermagem tem mais um recurso a utilizar em seu plano de cuidados.

\section{DISPNÉIA}

A dispnéia é outra complicação relacionada à falta de ar ou encurtamento da respiração, o idoso tem a sensação de não conseguir "pegar mais ar" ou não conseguir respirar profundamente. Isto se justifica pelo enrijecimento da musculatura pulmonar que pode ser causada pela presença de doenças crônicas não transmissíveis como: doença pulmonar obstrutiva crônica, fibrose pulmonar, embolia pulmonar, insuficiência do coração, asma, nervosismo.

No presente estudo, a dispnéia apresentou-se em vinte por cento dos idosos; no período pós-operatório fica difícil estabelecer o motivo da dificuldade da função respiratória no idoso. Além da perda funcional da idade, outros fatores pré-operatórios podem contribuir para o prejuízo da função pulmonar, como: o fumo, doenças pulmonares obstrutivas e exposição ambiental a poluentes, além dos efeitos das combinações farmacológicas, e anestésicos usados no processo anestésico cirúrgico ${ }^{(37)}$.

Em seu estudo com 234 pacientes, Shauna ${ }^{(27)}$ refere que o índice de complicações pós-operatórias na sala de recuperação pós-anestésica foi 23,4\%. Assim, a dificuldade respiratória constitui-se na complicação mais freqüente $(39,5 \%)$, seguida de náusea e vômito (30,5\%), taquicardia (13\%), hipertensão (10,5\%) e hipotensão (6,5\%). Do total de pacientes que apresentou complicações na recuperação pós-anestésica, 50,8\% requereram algum suporte ventilatório com a utilização de oxigênio; desses, 94\% 
usaram máscara nasal, 5,6\% precisaram de estimulação verbal e $0,4 \%$ precisaram ser reintubados.

\section{OUTRAS COMPLICAÇÕES: TAQUICARDIA E BRADICARDIA}

A avaliação da freqüência, da amplitude e do ritmo dos pulsos periféricos possibilita uma indicação da função cardíaca e da perfusão dos tecidos periféricos. ${ }^{(108)}$

No presente estudo, dentre as arritmias, a taquicardia $(10,9 \%)$ e a bradicardia $(8,2 \%)$ foram as complicações que se apresentaram com menor frequiência. Leykin et al. ${ }^{(62)}$ em seu estudo avaliaram as atividades realizadas na Unidade de Recuperação Anestésica no primeiro ano de funcionamento;onde 1.047 pacientes foram estudados, dos quais $(13,5 \%)$ apresentaram complicações cardiovasculares, entre elas, as arritmias como taquicardia $(2,6 \%)$ e bradicardia $(2,5 \%)$.

Valores similares foram encontrados no estudo de Rose et al. ${ }^{(109)}$ em 1,300 pacientes submetidos à cirurgia abdominal e sob anestesia geral. O índice de complicações na sala de recuperação pós-anestésica foi de $(2,5 \%)$ para taquicardia e $(0,9 \%)$ para bradicardia. Os autores referem que embora, ambas as complicações apresentem frequiências baixas, elas estão associadas a complicações de origem cardíaca ao longo do tempo. 
5.3 Discussão dos resultados referentes à associação entre as complicações mais freqüentes em sala de recuperação pós-anestésica e fatores de risco relacionados ao paciente cirúrgico idoso no período pré-operatório.

Em todo procedimento cirúrgico, fatores como idade, presença de doenças de base como a hipertensão arterial sistêmica, o escore ASA, tempo de cirurgia, tipo de cirurgia e tipo de anestesia são informações essenciais para adoção de medidas preventivas. Este estudo analisou 110 prontuários de pacientes idosos submetidos à cirurgia, procurando verificar a associação entre os fatores supracitados com as complicações apresentadas na sala de recuperação pós-anestésica.

A faixa etária que maior predominou nos idosos foi de 70 a 79 anos. Este dado corrobora os encontrados por Shahir et al. ${ }^{(58)}$, em que se observou que a chance de apresentar complicações pós-operatórias foi quase duas vezes mais, para pacientes maiores de 70 anos, quando comparados com pacientes entre 60 a 69 anos. Esta associação foi maior para pacientes com co-morbidade quando comparado a pacientes sem co-morbidade.

Associações similares, também, foram observadas no estudo de Polanczyk et al. ${ }^{(110)}$. Assim, as complicações pós-operatórias ocorreram em 4,3\% para pacientes com menos de 59 anos, 5,7\% para pacientes entre a faixa etária de 60 a 69 anos, 9,6\% para pacientes entre 70 a 79 anos e $12,5 \%$ em pacientes com idade acima de 85 anos. Com base nestes resultados, os autores referem que, quanto maior a idade, maior a chance de apresentar complicações após as cirurgias não cardíacas. Entre as complicações mais 
freqüentes, evidencia-se alta prevalência de dispnéia e hipotermia (35\% e 21\%) respectivamente. Os autores concluem que, se a avaliação pré-operatória estiver direcionada somente ao risco cardíaco podem ser negligenciados outros dados clínicos importantes para determinar o risco cirúrgico do idoso.

No estudo de Nishida et al. ${ }^{(61)}$, a população foi classificada em dois grupos: de 65 a 79 anos e maiores de 80 anos. Os autores encontraram em seus resultados complicações significativamente altas $(41 \%)$ aos pacientes maiores de 80 anos quando comparados a pacientes na faixa etária de 65 a 79 anos (21,3\%), constituindo-se as complicações pulmonares entre as mais freqüentes $(52,7 \%)$, seguidas das cardíacas $(19,4)$ e infecções do sítio cirúrgico $(11,1 \%)$.

Ao se analisar a associação entre hipertensão arterial sistêmica no período préoperatório com as diferentes complicações na sala de recuperação anestésica, verificouse maior chance de se apresentar a bradicardia e taquicardia Estes dados são condizentes com Samain et al. ${ }^{(86)}$ quando referem que os resultados pós-operatórios de qualquer procedimento cirúrgico estão associados com as doenças de base do paciente. Segundo os autores, a presença dessas doenças é elevada em pacientes idosos, assim, 50\% de pacientes submetidos a cirurgias não cardíacas tinham história de hipertensão, 30\% de doenças da artéria coronária, $15 \%$ relacionadas com insuficiência do coração, $17 \%$ às arritmias. Portanto, a chance de apresentar complicações pós-operatórias aumenta com o número de doenças associadas, como a hipertensão arterial. Ainda, salienta-se também a importância da avaliação no período pré-operatório, focada na estabilização da condição clínica do paciente. 
Este valor foi similar ao encontrado por Leung; Dzankic ${ }^{(111)}$, cujas complicações pós-operatórias foram observadas e registradas até o dia da alta hospitalar. Neste estudo, 77,6\% de pacientes desenvolveram eventos adversos no período intra-operatório, sendo a hipertensão arterial o evento mais comum. Já, no período pós-operatório, $21 \%$ dos pacientes desenvolveram um ou mais eventos adversos, de todos esses, os relacionados com o sistema cardiovascular foram as principais causas de morbidade, seguidas de complicações neurológicas e pulmonares.

Com relação à associação com a condição física do paciente segundo o escore ASA, nesta pesquisa obteve-se maior associação com a hipertensão arterial na SRPA. Estes resultados são condizentes com os encontrados na literatura.

Alguns fatores incrementam o risco de apresentar hipertensão na sala de recuperação pós-anestésica, incluindo, idade, fumo e doença renal. Além disso, a duração da cirurgia de mais de 4 horas incrementa a chance de apresentar hipertensão arterial, pacientes que apresentam hipertensão em sala de cirurgia, possivelmente também o façam na sala de recuperação pós-anestésica.

Assim, no estudo de Haddawi et al. ${ }^{(29)}$ as complicações pós-operatórias foram estratificadas, segundo a gravidade da doença, mediante o escore Complication Stratification and Severity Score. Na análise, os escores de gravidade das doenças foram associados com a classificação do estado físico segundo a ASA. Os resultados mostraram uma relação proporcional entre o escore ASA com a gravidade da doença. Portanto, os autores concluem que o êxito das cirurgias em idosos com 85 anos ou mais dependerá do estado clinico pré-operatório refletido na classificação ASA. 
O estudo de Gonzáles ${ }^{(30)}$ mostra um número maior de pacientes, dentre as classificações ASA II e III. O autor refere que os idosos provavelmente sempre estarão classificados entre esses graus do escore ASA, precisamente pela elevada prevalência de doenças crônicas não transmissíveis nesta fase da vida.

Além do escore ASA, a existência de outras escalas, como já foi citado ${ }^{(71,72,73)}$, atualmente são utilizadas na predição de eventos cardíacos pós-operatórios em pacientes submetidos a cirurgias cardíacas. Em seu estudo Heinisch et al. ${ }^{(12)}$ compararam a eficácia das três escalas mencionadas entre elas. Obtiveram como resultado a ausência de diferenças significativas. Concluíram que as escalas de índice cardíaco têm valor limitado na predição de eventos cardíacos. Este resultado, segundo o autor, é atribuído à exclusão de certos fatores como a dificuldade na intubação, perda sangüínea transoperatória, infecção de ferida, entre outros que poderiam contribuir indiretamente na apresentação de complicações cardíacas. Outra razão que limita a eficácia desses índices de risco é que, muitas vezes, são adequados para determinados grupos de pacientes.

Independente do escore utilizado, atualmente, os clínicos enfrentam um desafio ao estimar o risco cirúrgico dos pacientes. Pois, o propósito da avaliação não é dar simplesmente autorização para a cirurgia, é mais que tudo, fornecer o perfil clínico do risco operatório e das possíveis complicações que poderiam se apresentar no período pós-operatório, informações que também auxiliarão ao cirurgião, anestesista e a enfermeira a tomar a decisão mais acertada quanto à terapêutica.

No contexto perioperatório, é importante salientar que fatores de risco conhecidos como os estudados aqui, continuam sendo prognóstico de complicações na recuperação pós-anestésica. 
5.4 Discussão dos resultados referentes à associação entre as complicações mais freqüentes em sala de recuperação pós-anestésica e fatores de risco relacionados ao paciente idoso cirúrgico no período intra-operatório.

Quanto ao tempo de cirurgia, os pacientes submetidos a procedimentos realizados por mais de 5 horas tiveram maior possibilidade de apresentar hipertensão arterial. Estes dados foram corroborados por Recart ${ }^{(113)}$ quando conclui-se que, além dos fatores pré-operatórios, os fatores intra-operatórios, como o tempo de cirurgia maior a quatro horas, aumentam o risco de apresentar eventos cardíacos e respiratórios, prolongando dessa forma o tempo de recuperação pós-anestésica.

Araújo et al. ${ }^{(101)}$ referem que o tempo utilizado pelo cirurgião ao tentar mostrar as imagens aos médicos em treinamento influencia o tempo cirúrgico e, conseqüentemente, ultrapassa o tempo estimado da cirurgia. Assim em seu estudo, na maioria dos procedimentos cirúrgicos minimamente invasivos, o tempo passou de 45 minutos. Embora, este tempo seja inferior ao apresentado em nossos resultados, vale a pena considerar este tipo de observação que, de alguma forma, interfere prolongando o tempo cirúrgico.

Considerando que, quanto menor o tempo da cirurgia, menores serão as complicações pós-operatórias. Künzle et al. ${ }^{(51)}$ referes que, durante a cirurgia se devem ser reduzidos os fatores agressivos como: exposição e manipulação excessiva dos tecidos, minimizar o tempo de respiração por meio de aparelhos e executar o ato operatório no menor tempo possível. 
Em relação à posição cirúrgica, Rosher $^{(114)}$ refere que o posicionamento do paciente é um dos fatores chave para o sucesso da cirurgia, já que a maioria das alterações fisiológicas associadas com posicionamento está relacionada aos efeitos gravitacionais nos sistemas cardiológico e respiratório.

Além disso, podem ser incluídos outros fatores intrínsecos e extrínsecos da posição cirúrgica associada ao desenvolvimento de complicações pós-operatórias. Dentre os fatores intrínsecos, incluem-se a mobilidade, idade avançada, desnutrição, presença de co-morbidades (diabetes) e medicações. Já os fatores extrínsecos, referemse à pressão dos pontos ósseos, fricção, hiperextensão e tricotomia ${ }^{(115)}$.

Os resultados deste estudo mostram que a posição decúbito lateral apresentou maior associação com hipotermia, náusea, vômito e dor. $\mathrm{Na}$ literatura, não se encontraram evidências mostrando a associação com estas complicações, porém a posição decúbito lateral apresentou associação com outros fatores.

Assim, no Estudo de Stevens et al. ${ }^{(115)}$ foi determinada a incidência de úlcera por pressão em pacientes submetidos à cirurgia renal, os quais foram posicionados e segurados na mesa de cirurgia com faixas vs Vac Pac (aparelho sobre o qual o paciente é posicionado). De 382 pacientes, 250 (65\%) foram do sexo masculino e 132 (35\%) do sexo feminino, sendo a média de idade 47 anos, o tempo de cirurgia variou em torno de 257 minutos, $(14,4 \%)$ pacientes tiveram indícios de desenvolver úlcera por pressão, dos quais a maioria foi de grau I (64\%). Pela análise de regressão logística, a posição decúbito lateral e o tempo de cirurgia apresentaram-se como fatores de risco associados ao desenvolvimento de úlcera por pressão. Os autores referem que estes resultados são superiores aos encontrados no estudo Aronovitch ${ }^{(16)}$, cuja incidência de ulceras por 
pressão foi menor do que $1 \%$. Nesse estudo, os pacientes foram submetidos a cirurgias cardíacas, sendo na maioria dos casos adotada a posição supina.

No estudo de Michaels et al. ${ }^{(117)}$, os autores referem que nos diferentes procedimentos cirúrgicos, freqüentemente, não se toma cuidado com o posicionamento dos braços do paciente na mesa cirúrgica. Posicionando o braço em abdução maior que $90^{\circ}$, hiperextensão e rotação interna da cabeça do úmero provocando o estiramento e, conseqüentemente, dano do plexo braquial.

Portanto, os autores determinaram o índice de complicações pós-operatórias como: trombose venosa profunda e dano do plexo braquial em pacientes submetidos a prostatectomia radical. Com esta finalidade, posicionaram os pacientes em trendelemburg para facilitar o retorno venoso, com a posição dos braços sobre o peito formando um X. Em seus resultados, este posicionamento mostrou-se eficiente, já que só um paciente apresentou trombose venosa profunda e nenhum mostrou dano do plexo braquial. $\mathrm{O}$ autor concluiu que embora o dano do plexo braquial não fosse comum, também representa uma co-morbidade no período pós-operatório.

No presente estudo, apesar da posição supina ser a mais freqüente em razão do tipo de cirurgia (abdominal) os dados da análise mostram que o paciente posicionado em decúbito lateral apresenta maior risco de complicações na sala de recuperação pósanestésica. Isto se pode atribuir a fatores, como: distribuição do peso corporal irregular, maior área de exposição corporal, diferença na perfusão/ventilação de ambos pulmões e hiperextensão dos membros superiores.

Quanto aos tipos de cirurgia, neste estudo evidenciou-se que a artroplastia teve maior associação com náusea e vômito na sala de recuperação pós-anestésica. Vale 
salientar que estes procedimentos cirúrgicos, com freqüência, são realizados no idoso. $\mathrm{O}$ grande aumento de incidência destas cirurgias na faixa etária acima dos 65 anos deve-se, sobretudo à instalação da osteoporose, bem como à maior incidência de quedas. Apesar de medidas na prevenção de quedas, tratamento precoce da osteoporose, incentivo à atividade física regular e o controle de outras doenças, as fraturas continuam sendo freqüientes no idoso ${ }^{(91,118)}$.

O predomínio de náusea e vômito, segundo Anderson et al. ${ }^{(107)}$, apresentam uma variação de $10 \%$ a $60 \%$, o que depende da presença de outros fatores como: idade, gênero, tipo de cirurgia, tipo de anestesia e tempo de cirurgia.

Autores $^{(119,120,121)}$ têm relatado que os pacientes submetidos a este tipo de procedimento cirúrgico, após cirurgia experimentam dor, o que deve ser tratado imediatamente. Dentre os diversos tratamentos para aliviar a dor neste período, as medidas medicamentosas têm sido abordadas com frequiência. Contudo, deve-se lembrar que, alguns desses medicamentos podem provocar náuseas e vômitos no período de recuperação anestésica.

Isso pode ser corroborado por Fetzer et al. ${ }^{(122)}$, em cujos resultados $50 \%$ dos pacientes reportaram sintomas de náusea e vômito no pós-operatório. Neste estudo, os pacientes foram perguntados sobre a opinião das causas desses sintomas. Assim, (36\%) atribuíram às medicações para dor; $(13,4 \%)$ reportaram que a dor era causada por náuseas e vômitos; $(24,3 \%)$ atribuíram à anestesia; $(17,6 \%)$ à movimentação e $(7,1 \%)$ ao jejum do pré-operatório.

Outro estudo atribuiu esta associação à técnica analgésica após o procedimento cirúrgico. Se bem que os resultados mostraram similares efeitos analgésicos para as 
diferentes técnicas, mas todas estavam associadas a uma alta incidência de náusea e vômito no período pós-operatório ${ }^{(96)}$.

Pode-se verificar que esse tipo de complicações também se apresenta em outros tipos de cirurgias. Assim, Marcelino; Peniche ${ }^{(13)}$ no estudo de revisão bibliográfica (1995-2000) sobre cirurgias videolaparoscópicas, observaram que as náuseas e vômitos foram as complicações mais comuns no período de recuperação anestésica, seguidas de eventos de diarréia, refluxo gastroesfágico, epigastralgia, disfagia, regurgitação, dispnéia, acidose respiratória e dor.

Pelos dados da Tabela 5, evidencia-se associação da anestesia raquidiana com taquicardia no período pós-operatório. Estes dados não são condizentes com a literatura, pois, segundo Ortenzi ${ }^{(123)}$ os efeitos fisiológicos deste tipo de anestesia são basicamente a queda da freqüência cardíaca (FC) e da PA.

Por outro lado, autores ${ }^{(124,125)}$ referem que a etiologia da taquicardia no período pós-operatório varia, podendo ser influenciada por fatores, como: hipovolemia, embolismo pulmonar, anormalidades eletrolíticas ansiedade e dor.

Pautado nisso, pode-se inferir que, além do tipo de anestesia, outros fatores como os relacionados com os processos de ansiedade e as medicações para dor (opióides) tenham influenciado nas respostas autonômicas, desencadeando a aparição de taquicardia nesse período ${ }^{(123)}$.

Nos procedimentos cirúrgicos do paciente idoso, pode-se verificar que as variáveis cirúrgicas, como: tipo de anestesia e tempo de cirurgia, acabam repercutindo no âmbito dos diferentes sistemas, influenciando a apresentação de complicações na 
recuperação pós-anestésica, sendo exacerbadas pelas perdas gradativas das funções orgânicas.

Diante isso, ações médicas ou cirúrgicas devem ser adaptadas às alterações fisiológicas do idoso para poder minimizar o índice das complicações, após as cirurgias nesta população. Por outro lado, cabe ao enfermeiro da unidade de recuperação pósanestésica estar atento(a) e preparado(a) quando estas complicações apresentarem-se, agindo de maneira rápida e efetiva. Neste sentido, a observação no período necessita ser constante até que as funções vitais sejam totalmente estabilizadas. 
Conclusões 


\section{CONCLUSÕES}

Os resultados levam as seguintes conclusões:

Os fatores de risco, identificados no paciente cirúrgico idoso, no período pré-operatório foram: o sexo masculino, a idade entre 70 a 79 anos, a hipertensão arterial sistêmica como patologia de base, e o estado físico II do paciente segundo a Associação Americana de Anestesiologistas (ASA ). Os fatores de risco, que se apresentaram com maior incidência no paciente cirúrgico idoso, no período intra-operatório foram: o tempo cirúrgico inferior a 3 horas, posicionamento na sala de cirurgia em decúbito lateral, as cirurgias abdominais, e a anestesia geral.

As complicações mais freqüentes apresentadas na sala de recuperação pósanestésica foram: a hipotermia, dor, hipertensão arterial, náusea e vômito, dispnéia e arritmias.

A associação entre os fatores de risco do paciente cirúrgico idoso no período pré-operatório com as complicações na sala de recuperação pósanestésica foram: ambos os sexos apresentaram associação com todas as complicações na sala de recuperação pós-anestésica; a faixa etária entre 70 a 79 anos apresentou maior associação com a dispnéia e taquicardia; pacientes com hipertensão tiveram maior associação com arritmias, o 
estado físico do paciente segundo a ASA apresentou maior associação com hipertensão arterial sistêmica.

A associação entre os fatores de risco do paciente cirúrgico idoso no período intra-operatório com as complicações na sala de recuperação pósanestésica foram: o tempo cirúrgico entre três a cinco horas apresentou maior associação com dor; a posição em decúbito lateral apresentou maior associação com hipotermia, náusea, vômito e dor na sala de recuperação pós-anestésica, dos tipos de cirurgia, as artroplastias apresentaram maior associação com náusea e vômito, e anestesia raquidiana apresentou maior associação com taquicardia. 


\section{Referências}




\section{REFERÊNCIAS}

1. Papaléo Netto M, Salles RFN. Fisiologia do envelhecimento: aspectos fundamentais. In: Papaléo Netto M, Brito FC. Urgências em geriatria. São Paulo: Atheneu; 2001. p. $1-8$.

2. Paschoal SMP. Autonomia e independência. In: Papaleão Netto M. Gerontologia. A velhice e o envelhecimento em visão globalizada. São Paulo: Atheneu; 1996. p.31323.

3. Organización Mundial de la Salud. Aplicación de la epidemiología al estudio de los ancianos: informe de un grupo científico de la OMS. Genebra, 1994. (Série Informe Técnico n. 706).

4. Feliciano AB, Alves de Moraes S, Martins de Freitas IC. O perfil do idoso de baixa renda no Município de São Carlos, São Paulo, Brasil: um estudo epidemiológico. Cad. Saúde Pública, 2004; 20 (6):1575-1585.

5. Nunes TA. Limites da cirurgia no paciente idoso. In: Petroniau A, Pimenta LG. Cirurgia Geriátrica. Rio de Janeiro: Medsi; 1998. p. 309-13.

6. Instituto Brasileiro de Geografia e Estatístico. Disponível em: http: //www.ibge.gov.br.

7. Palloni A, Peláez M, Histórico e natureza do estudo. In: Lebrão ML, Duarte YAO. SABE - Saúde Bem-estar e Envelhecimento. O projeto SABE no Município de São Paulo, uma abordagem inicial. Brasília: Organização Pan-Americana da Saúde; 2003. p. 15-32.

8. Orb A. Aspectos de salud en adultos mayores de 80 años de edad que viven independientemente en la comunidad: una perspectiva Austrialiana. Rev Latino-am Enfermagem 2004; 12(4): 589-96.

9. Tramontini CC, Lopez DFM, Kikuchi EM, Kemmer LF, Granhani ML. Repensando a formação do gerente do processo de trabalho do enfermeiro do Centro Cirúrgico e central de material. Rev Sobecc 2002; 7 (1): 11-15.

10. Sociedade Brasileira de Enfermeiros de Centro Cirúrgico, recuperação anestésica e central de material e esterilização. Práticas Recomendadas. $3^{a}$ ed. São Paulo; 2005 (SOBECC).

11. Araújo IEM, Lamas JLT, Ceolim MF, Bajay HM. Sistematização da assistência de enfermagem em uma unidade de internação: desenvolvimento e implementação de 
roteiro direcionador; relato de experiência. Rev Acta Paul Enferm 1996; 9(1):1827.

12. Peniche ACG. Abrangência da atuação do enfermeiro em sala de recuperação anestésica como perspectiva de melhor assistência ao paciente no período perioperatório. Rev Esc. Enferm USP 1995; 29(1):83-90

13. Marcelino AA, Peniche A de CG. Complicações no período pós-operatório de cirurgia videolaparoscópica. Rev Paul Enf. 2002; 31(3): 280-6.

14. Hutchisson B, Phippen ML, Wells MP. Review of perioperative nursing. Philadelphia: Copyright; 2000. p. 83-90.

15. Diogo MJD, Paschoal SMP, Cintra FA. A avaliação global do idoso. In: Duarte YA, Diogo MJD. Atendimento domiciliar: um enfoque gerontológico. São Paulo: Atheneu; 2000. p. 145-171.

16. Leite RCB. Percepção da assistência de enfermagem em relação ao idoso. [tese] São Paulo (SP): Escola de Enfermagem da USP; 2002.

17. Protti ST. A saúde do idoso sob a ótica da equipe do programa de saúde da família.[tese] Ribeirão Preto (RP): Escola de Enfermagem de Riberão Preto; 2003.

18. Wong DH, Weber EC, Schell MJ, Wong AB, Anderson CT, Barker SJ. Factors associated with postoperative pulmonary complications in patient with severe chronic obstructive pulmonary disease. Rev Anesthesiol. Analg 1995; 80: 276-84.

19. Comitê de Recomendações Práticas da AORN. Recomendações práticas para a documentação do cuidado de enfermagem perioperatória. Rev SOBECC 2002; 7(1):8-10.

20. Matos NL. Assistência de enfermagem ao idoso em situação cirúrgica. In: Petroianu A, Pimenta LG. Cirurgia geriátrica. Rio de Janeiro: Medsi; 1998. p. 357-362.

21. Peniche ACG. A ansiedade e o paciente cirúrgico: análise das variáveis intervenientes. [tese] São Paulo (SP): Escola de Enfermagem da USP; 2005.

22. Matisson RA. Cuidados e complicações pós-anestésicos. In: Dukes J. Segredos em anestesiologia.Trad. de Wilson HD. $2^{\mathrm{a}}$ ed. Porto Alegre: Artmed; 2003.

23. César CLG. Fatores de risco associados à mortalidade infantil em Cotia e Vargem Grande Paulista: uma proposta de instrumentos preditivos. [tese] São Paulo (SP): Faculdade de Saúde Pública da USP; 1989. 
24. Barreto J. Avaliação prospectiva do risco cardiopulmonar em cirurgia abdominal alta eletiva. [tese] São Paulo (SP): Escola Paulista de Medicina/UNIFESP; 2000.

25. Goldberg M. Obscuro objeto da epidemiologia. In: Breilh J, Goldberg M, Barreto ML, Almeida MF, Costa NR, Gonçalves RBM. Epidemiologia teoria e objeto $3^{\mathrm{a}}$ ed. São Paulo: Hucitec-Abrasco; 2002. p. 87-113.

26. Operative complications. Medical Dictionary [on-line]. Califórnia; 2004. Disponível em: http://cancerweb.ncl.ac.uk/cgi-bin/omd?complication

27. Shauna ET. A description intraoperative of postanesthesia complications rates. $\mathrm{J}$ of Perianethesia Nursing 2006; 21(2): 88-96.

28. Mayson K. The incidence of postoperative complications in the PACU. [abstract]. Can J Anesthes 2005; 52: A62.

29. El-Haddawai F, Abu-Zidan FM, Jones W. Factors affecting surgical outcome in the elderly at Auckland hospital. ANZ J Surg. 2002; 72(8):537-41.

30. Morales Gonzáles RA. Mortalidad posoperatoria intrahospitalaria de los adultos mayores en cirugía general. Rev Cubana Cir [periódico online]. 2003;42(4). Disponível em: $\quad$ http://scielo.sld.cu/scielo.php?script=sci_abstract\&pid=S003474932003000400006\&lng=pt\&nrm=iso\&tlng=en. [Acesso em 18 out. 2006].

31. Silva FSC. Abdome agudo. In: Papaléo Netto M, Brito FC. Urgências em geriatria. São Paulo: Atheneu; 2001. p. 261-72.

32. Rezende ALM. O paciente geriátrico face à cirurgia. Rev Bras.Enf; DF; 1976, 28:38-47.

33. Ordaz JLM, Moreno RMS, Luque-de Leon E, Blanco-Benavides R. Fistulas enterocutáneas en pacientes mayores de 70 años. Rev Cir Cirurj 2004; (72):281285.

34. Vasconcelos Filho PO, carmona MJC, Auler Junior JOC. Peculiaridades no pósoperatório de cirurgia cardíaca no paciente idoso. Rev Bras. Anestesiol 2004; 54(5): 88-109.

35. Parker M, Gurusamy K, Stoker M. Surgery in elderly patients. Current Orthopaedics 2004; 18: 333-344.

36. National High Blood Pressure Education Program. The Seventh Report of the Joint National Committee on Prevention, Detection, Evaluation and Treatment of High Blood Pressure. Bethesda 2004. 
37. Chan ED, Wellsh CH. Geriatric respiratory medicine. Chest, 1998; 114: 17041733.

38. Fernandes CR, Ruiz Neto PP. O sistema respiratório e o idoso: implicações anestésicas. Rev Bras Anestesiol. 2002;52(4):461-70.

39. Waitzberg DL. Avaliação nutricional do doente crítico. In: Gonçalves EL. Nutrição e cirurgia. São Paulo: Sarvier; 1998. p. 87-98.

40. Tompkins RG, Welch CE. Cirurgia: Avaliação pré-operatória e tratamento intra e pós-operatórios. In: Abrams WB, Berkou R. Manual Merck de Geriatria. São Paulo: Roca; 1995. p. 239-264.

41. Pessuto J, Carvalho EC. Fatores de risco em indivíduos com hipertensão arterial. Rev Latino-Am.Enfermagem. Riberão Preto; 19986 (1): 33-39.

42. Oliveira AC. Infecção do sitio cirúrgico em pacientes submetidos a cirurgia do aparelho digestivo: uma proposta de predição de risco. [tese]. São Paulo: Escola de Enfermagem da USP; 2003.

43. Spielberger CD. Tensão e ansiedade. São Paulo: Harper \& Row do Brasil; 1981.

44. Peniche ACG, Moraes LO. Ansiedade do paciente cirúrgico ambulatorial. Rev SOBECC 2003; 8(3):17-22.

45. Concon Filho A, Pinho Cláudio. O papel do cirurgião na avaliação operatória.Rev Soc Cardiol estado de São Paulo 2000; 3: 268-76.

46. Schamann DGT, Fortis EF, Pandikow HMA. Posição do paciente cirúrgico. 2002 [online]. Disponível em:<http www.famed.urfgs.br/disciplinas/med03377/ares/livro_ares/posicionamento.htm

47. Ferreira BLM, Ribeiro MMC. Centro Cirúrgico: O espaço de fazer da enfermagem. Rio de janeiro: EDC; 2000. p. 88-94.

48. McEwen DR. Intraoperative positioning of surgical patients-home: study program including question and answer key. AORN J. 1996;63(6):1059-86.

49. Rammohan NM. Principles of neuroanesthesia Journal AAORN 2004. Disponível em <http:// www.thamburaj.com/neuroanesthesia.htm (Setembro, 2005).

50. Lacerda RA. Centro Cirúrgico. In: Fernandes AT et al. Infecção hospitalar e suas interfaces na área da saúde. São Paulo: Atheneu; 2000. p. 789-818. 
51. Kunzle JE, Ziliotto A, Mendes JÁ, Pinto FC. Cuidados trans-operatórios no paciente idoso. In: Petroianu A, Pimenta LG. Cirurgia Geriátrica. Rio de janeiro: Medsi; 1998. p. 327-331.

52. Yang JH. Monitorizaçao e distúrbios da temperatura. In: Dukes J. Segredos em anestesiologia.Trad. de Wilson HD. $2^{\mathrm{a}}$ ed. Porto Alegre: Artmed; 2003.

53. Couto ES, De Faria MD, Andrade LO. Anestesia no paciente idoso. In: Petroniau A, Pimenta LG. Cirurgia Geriátrica. Rio de Janeiro: Medsi; 1998.

54. Lima Costa MF. Saúde Pública e envelhecimento. Editorial Cad. Saúde Pública 2003; 19(3): 700-703.

55. Sung VW, Weitzen Sh. Sokol ER, Rardin CHR, Myers DL. Effect of patient age on increasing morbidity and mortality following urogynecologic surgery. American Journal of Obstrtrics and Gynecology 2006; 194: 1411-7.

56. Wong J, Wong Sh, Brooks E. A study of hospital recovery pattern of acutely confused older patients folloeing hip surgery. Journal of Orthopaedic Nursing 2002; 6: 68-72.

57. Kojima Y, Narita M. Postoperative outcome among elderly patients after general anesthesia. Rev. Acta Anesthesiol Scand 2006; 50: 19-25.

58. Shahir MA, Lemmens VPEE, Van de Poll Franse LV, Voogd AC, Martijn H, Jansseng -Heining MLG. Elderly patients with rectal cancer have a higert risk of treatment-related complication and poorer prognosis than jounger patients: a population-based study. European Lournal of Cancer 2006; XXX-XXX.

59. Nguyen NT, Rivers R, Wolfe BM. Factors associates with operative outcomes in laparoscopic gastric bypass. J Am Coll Surg 2003; 197(4): 548-555.

60. Pessaux P, Tuech J, Derouet N, Rouge N, Regenet N, Arnaud P. Laparoscopic cholecystectomy in the elderly . Surgical Endocopy 2000; 14: 1067-1069.

61. Nishida K, Okinaga K, Miyazawa Y, Ssuki K, Tanaka M, Hatano M, et al. Emergency abdominal surgery in patients aged 80 years and older. Rev. Surg Today 2000; 30: 22-27.

62. Leykin Y, Costa N, Furian S, Nadalin G, Gullo A. Recovery Room. One-year experience. Rev Minerva Anesthesiology 2001; 67(7): 555-62. 
63. Lorentz MN, Santos AX. Hipertensão arterial sistêmica e anestesia. Rev Bras Anestesiol. 2005; 55(5): 56-42.

64. Sociedade Brasileira de Cardiologia. IV Diretrizes de hipertensão arterial. Arq Bras Cardiol 82(suplemento IV) 2004.

65. Aronson S. Hypertension: a new look at an ald problem. Current Opin Anaesthesiol 2006; 19: 59-64.

66. Howell SJ, Sear JW, Foëx P. Hypertension, hypertensive heart disease and perioperative cardiac risk. BR J Anaesth 2004; 92: 570-83.

67. Nunnelee JD, Spaner SD. Assessment and Nursing mamagement of hypertension in the operative period. J Perianesth Nurs. 2000;15(3):163-8.

68. Rego RE, Moricz A, Sila RA, Pacheco JAM. Tratamento cirúrgico da litíase vesicular no idoso: Análise dos resultados imediatos da colescistectomia por via aberta e videolaparoscópica. Rev Assoc Méd Brás 2003; 49(3): 293-9.

69. Aquino RB, Araújo de Souza AC, Argimon IL, Santos PF. Efeito da anestesia geral na cognição e na memória do idoso. Rev Bras Anestesiol. 2004;54(5): 68792.

70. Leme LEG, Carelli CDR. Peculiaridades do pré e pós-operatório dos pacientes idosos em procedimentos ortopédicos. Acta Ortopbras 1998; 6(1): 37-43.

71. Goldman L, Caldera DL, Nussbaum SR, Southwick FS, Krogstad D, Murray B, et al. Multifactorial index of cardiac risk in noncardiac surgical procedures. N Engl $\mathbf{J}$ Med. 1977;297(16):845-50.

72. Detsky AS, Abrams HB, MCLaughlin JR at al. Prediction cardiac complications in patients undergoing non-cardiac surgery. J Gen Intern Med 1986; 1: 211-9.

73. Larsen SF, Olesen KH, Jacobsen E, et al. Prediction of cardiac risk in non-cardiac surgery . Eur Heart J 1987; 8: 179-85.

74. Ricker LE. Posicionamento do paciente para a cirurgia. In: Meeker MH, Rothrock JC. Cuidados de Enfermagem ao paciente cirúrgico. 10 ed. Rio de Janeiro: Guanabara Koogan; 1997.p.90.

75. Widman J, Isacson J. Lateral position reduces blood loss in hip replacement surgery: a prospective randomized study of the 74 patients. International Orthopaedics (SICOT) 2001; 25:226-227. 
76. Hwang W, Jeon T, Kim H, Oh S, Park P. The effect of the lateral decubitus position on the intraocular pressure in anesthezed patients undergoing lung surgery. Acta Anaesthesiol Scand 2006, 50: 988-922.

77. Moraes de M, Rodrigues R, Milano C, Fijiki EM, Ono KK, Costa Pda. Estudo das fraturas peritrocanterianas instáveis do fêmur tratadas com haste céfalo-diafisiaria bloqqueada: técnica minimamente invasiva. Acta Ortopédica Brasileira, 2005 13(3): 153-55.

78. Ruedi TP, Murphy WM: Placas em Ponte, Princípios do Tratamento de Fratura. São Paulo: ArtMed; 2002. p. 221-229.

79. Macedo CAS, Gália CR, Rosito R, Pere CEF, Muller LM, Verzoni GG, et al. Abordagem cirúrgica na artroplastia total primaria de quadril: Antero lateral ou posterior?.Rev bras Ortop 2002; 37(9): 387-391.

80. Walton B, Farrow C, Cook TM. A national survey of epidural use and management in elderly patients undergoing elective and emergency laparatomy. Anaesthesia 2006; 61: 456-461.

81. Malheiros APC, Texeira MC, Habr-Gama A, Martins de Alcântara OS. Resultados do tratamento cirúrgico do câncer de colo retal em doentes de idade até 64 e 65 anos ou mais. Rev bras Coloproct 2005; 25 (2):128-136.

82. McGory ML, Shekelle PG, Rubenstein L, Fink A et al. Developing quality indicators for elderly patients undergoing abdominal operations. J Am Coll Sur 2005; 201: 870-883.

83. Collet e Silva FS. Abdome Agudo. In: Papaleão Netto M, Carlos de Brito F. Urgências em Geriatria. São Paulo: Atheneu; 2001.

84. Tan KG, Chen CH M, Chin NG, Tan SM, et al. Wichs octogenarians do pooly after major open abdominal surgery in our Asian Population. World J Surg 2006; 30: 547-552.

85. Heriot A, Tekkis PP, Smith JJ, Cohen CR, Montgomery A, Audisio RA, et al. Prediction of postoperative mortality in elderly patients with colorectal cancer. Diseases of the colon\& rectum 2006; 49:6: 816-24.

86. Samain E, Schauvliège F, Deval B, Marty J. Anesthesia for breast cancer surgery in the elderly 2002. Critical Reviews in Oncology/Hematology 2003; 46:115-120.

87. Frank S. et al Perioperative maintenance of normothermia reduces the incidence of morbid cardiac events. A randomized clinical trial. JAMA 1997; 277: 1127-1134. 
88. Holm R. Postoperative hypothermia the chilling consequences. AORN J. 2006; 83(5): 1054-1068.

89. Sessler DI, Rubinstein EH, Moayeri A - Physiologic responses to mild perianesthetic hypothermia in humans. Anesthesiology, 1991;75:594-610.

90. Mahoney CB, Odom J. Maintaining intraoperative normothermia: a meta-analisys of outcomes with costs. AANA J. 1999;67(2):155-63.

91. Smeltzer SC, Bare BG. Brunner \& Suddarth: tratado de enfermagem médicocirúrgica. 9a ed. Rio de Janeiro: Guanabra Koogan; 2002. 2 v.

92. Matsukawa T, Sessler DI, Sessler AM et al - Heat flow and distribution during induction of general anesthesia. Anesthesiology, 1995;82:662-673.

93. Biazzotto Camila B., Brudniewski Márcio, Schmidt André P., Auler Júnior José Otávio Costa. Hipotermia en el período perioperatorio. Rev. Bras. Anestesiol 2006; 56(1): 89-106.

94. Garavello A, Manfroni S, Antonellis A. Postoperative pain in prosthetic inguinal hernioplasty. Predictive factors and effects on patient recovery. Rev. Minerva Chir. 2001; 56(6): 561-5.

95. Leardi S, Felici S,. Maria E, Antonellis M, Pietroletti R, Simi M. Postoperative pain as complication hérnia surgical repair with mesh and plug. Rev. Chir Italy 2003; 55 (6): 887-91.

96. Shapiro A, Zohar E, Hoppensteing D, Ifrach N, Jedeikin R, Fredman B. A comparison of three techniques for acute postoperative pain control following major abdominal surgery. Journal of Clinical Anesthesia 2003; 15: 345-350.

97. Chaves LD, Pimenta CA. Postoperative pain control: comparison of analgesic methods. Rev Lat Am Enfermagem 2003 Mar-Apr; 11(2):215-9.

98. Chung JW, Lui JC. Postoperative pain management: study of patients' level the pain and satisfaction with health care providers' responsiveness to their reports of pain. Nurs Health Sci. 2003;5(1):13-21.

99. Maggio C, Bonzano A, Cante E, et al. Pré-operative evaluation in non-cardiac surgery: cardiac risk assessment. Healt Care 1992, 4: 217-24.

100. Foëx P, Sear JW. The surgical hypertensive patient. Critical Care \& Pain 2004; 4(5): 139-143. 
101. Araujo LMTde, Klamt JG, Garcia LV. Anestesia para ressecção transuretral de próstata: comparação entre dois períodos de um Hospital Universitário. Rev Bras Anesthesiol 2005; 2: 197-206

102. Eberharth LH, Morin AM, Wulf H, Geldner G. Patients preference for immediate postoperative recovery. Br J Anaesth. 2002;89(5):760-9.

103. Lages N, Fonseca C, Neves A, Landeiro N, Abelha JF. Náuseas e vômitos no pósoperatório: Uma revisão do "pequeno grande" problema. Rev Bras Anestesiol 2005; 55 (5): 575-585.

104. Twersky RS. Recovery and discharge of the ambulatory the anesthesia patient. 2005 Brooklyn New York.

105. Harvey AB. Postoperative nausea and vomiting in the recovery room. A report from Guyana. West Indian Med J 2001; 50(1): 31-6.

106. Abreu MPde, Vieira JL, Ferreira da Silva I, Miziara LEP, Fófano R. Eficácia do ondansetron, metoclorpraprida, droperidol, e dexametasona na prevenção de náusea e vômito após laparoscopia ginecológica em regimen ambulatorial: estudo comparativo. Rev Bras Anesthesiol 2006; 56(1): 8-15.

107. Anderson LA, Gross JB. Aromatherapy with peppermint, isopropyl alcoho, or placebo is equally effective in relieving postoperative nausea. Journal of Perianesthesia Nursing 2004; 19(1): 29-35.

108. Luecknotte A Avaliação em Gerontología. $3^{\mathrm{a}}$ ed. São Paulo: Reichmann \&Affonso, 2002.

109. Rose D, Keith MD, Cohen M, DeBoer DP. Cardiovascular events in the postanesthesia care unit: contribution of risk factors. Anesthesiology 1996; 84(4): 772-781.

110. Polaczyk CA, Marcantonio E, Goldman L, Rhode L, Orav J, Mangioni C, Lee T. Impact of age on perioperative complications and leght of stay in patients undergoing noncardiac surgery. Annals of internal medicine 2001; 134(8): 637643.

111. Leung JM, Dzankic S. Relative importance of preoperative health status verus intraooperative factors in predicting postoperative adverse outcomes in geriatric surgical patients. J Am Geriatr Soc. 2001;49(8):1080-5. 
112. Heinisch RE, Barbieri CF, Nunes Filho JR, Oliveira GLde, Heinisch LMM. Avaliação prospectiva de diferentes índices de risco cardíaco para pacientes submetidos a cirurgias não cardíacas. Arq. Bras Cardiol 2002; 79(4): 327-32.

113. Recart A, Gasanova I, White PF, Thomas T, Ogunnaike B, Hamza M. The effect of cerebral monitoring onrecovery after general anesthesia: A comparison of the auditory evoked potencial and bispectral index devices with standar clinic practice.Anesth Analg 2003; 97: 1166-1674.

114. Rosher JW. Posicionamento do paciente. In: Segredos em anestesiologia. Duke J. $2^{\mathrm{a}}$ ed. Porto Alegre: Artmed, 2003 p. 136.

115. Stevens J, Nichelson E, Linehan M, Thompson N, Liewehr D, Venzon D,et al. Risk factors for skin breakdown after renal and adrenal surgery. Adul Urology 2004; 64: 246-49.

116. Aronovitch SA. Intraoperative adquired pressure ulcer prevalence: a national study. Adv Wound Care 1998; 11: 8-9.

117. Michaels MJ, Lish MC, Mohler JL. Patient positioning for radical retropubic prostatectomy. Urology. 1998;51(5):824-6.

118. Sakaki MH, Oliveira AR, Coelho FF, Leme LEG, Suzuki I, Amatuzzi MM. Estudo na mortalidade de fratura de fêmur no paciente idoso. Acta ortop. bras. 2004; 12 (4): 35-9.

119. Imbelloni LE, Beato L. Comparação entre raquianestesia, bloqueio combinado raqui-peridural e raquianestesia contínua para cirurgias de quadril em pacientes idosos: estudo retrospectivo. Rev. Bras Anestesiol 2002; 52(3): 16-24.

120. Fonseca NM, Ruzi RA, Ferreira FX, Arruda FA. Analgesia pós-operatória em cirurgia ortopédica: estudo comparativo entre o bloqueio do plexo lombar por via perivascular inguinal (3 em 1) com ropivacaína e a analgesia subaracnóideia com morfina. Rev Bras Anestesiol 2003; 53(2): 188-197.

121. Ratan A, Habib E. El-Moalem, Tong J. Gan. Comparison of the morphine-sparing effects of diclofenac sodium and ketorolac tromethamine after major orthopedic surgery. Journal of clinical Anesthesia 2002; 14(3): 187-192.

122. Fetzer SJ, Hand MA, Bouchard PA, Smith HB, Jenkins MB. Self-cre activities for postdischarge nausea and vomiting. Journal of Perianesthesia Nursing 2005; 20(4): $249-254$ 
123. Ortenzi AV. Avaliação e medicação pré-anestésica. São Paulo: Saesp, 2002. p. 467497.

124. Durazzo AE, Caramelli B. Abordagem do paciente assintomático do ponto de vista cardiológico e com indicação de revascularização de aorta e seus ramos. Rev Soc Cardiol estado de São Paulo 2000; 10(3): 334-342.

125. Hoffer JL. Anestesia. In Meeker MH, Rothrock JC. Alexander: cuidados de enfermagem ao paciente cirúrgico. 10.ed. Rio de Janeiro: Guanabara Koogan; 1997. p.134-136. 
Anexos 


\title{
ANEXO A \\ UNIVERSIDADE DE SÃO PAULO / USP \\ PROGRAMA DE ENFERMAGEM / PÓS-GRADUAÇÃO EM ENFERMAGEM INSTRUMENTO DE COLETA DE DADOS
}

\author{
SEÇÃO I : ASPECTOS RELACIONADOS ÀS CARACTERÍSTICAS SÓCIODEMOGRÁFICAS \\ IDENTIFICAÇÃO \\ $\mathrm{N}^{\mathrm{o}}$ de instrumento \\ Data de Nascimento \\ Sexo (0) Masc (1) Fem \\ Escolaridade: (1) $1^{\circ} \mathrm{Grau}$ \\ (2) $2^{\circ} \mathrm{Grau}$ \\ (3) $3^{\circ}$ Grau \\ (4) Técnico \\ (5) Graduado \\ (6) Analfabeto
}

SEÇÃO II : ASPECTOS RELACIONADOS À CIRURGIA

COMORBIDADES

\begin{tabular}{|c|c|c|c|}
\hline 1) Hipertensão & 2) D Isq do coração ${ }^{125}$ & 3) $\mathrm{AVC} / \mathrm{DCV}^{125}$ & 4) Insuf. Cardiaca \\
\hline 5) Arritmias & 6) $\mathrm{DPOC}^{125}$ & 7) Pneumonia & 8) Epilepsia \\
\hline 9) Diabetes & 10) Algum tipo de $\mathrm{CA}^{125}$ & 11) Parkinson & 12) Cirrose \\
\hline 13) Osteoartrose & 14) Osteoporose & 15) Demencia & 16) Depressão \\
\hline 17) Anemia & 18) Desnutrição & 19) Tuberculose & 20) Hepatite \\
\hline 21) D. Degen. S.N.C. ${ }^{125}$ & 22) D. Ap.Digestivo ${ }^{125}$ & 23) Hepatite & 24) $\operatorname{AIDS}^{125}$ \\
\hline 25) Incontinencia Urinária & 26) $\mathrm{ITU}^{125}$ & 27) Insuf renal & 28) $\mathrm{DTS}^{125}$ \\
\hline 29) & $30)$ & $31)$ & 32) \\
\hline \multicolumn{2}{|c|}{ Hipertensão Arterial Sistêmica } & \multicolumn{2}{|c|}{ Estado físico segundo a (ASA) } \\
\hline Nível da Pressão Arterial & Classificação & 1) I & 4) IV \\
\hline$<120$ sistólica e $<80$ diastólica & Normal. & 2) II & 5) $\mathrm{V}$ \\
\hline 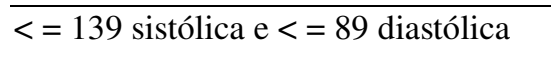 & Pré-Hipertensão. & 3) III & 6) VI \\
\hline 140 -159 sistólica ou 90-99 diastólica & Hipertensão Estágio 1. & \multicolumn{2}{|c|}{ Comportamento emocional na unidade } \\
\hline$>160$ sistólica ou $>100$ diastólica & Hipertensão Estágio 2. & $\begin{array}{l}\text { (1) Tranquilo } \\
\text { ansioso }\end{array}$ & (2) ansioso \\
\hline
\end{tabular}

SEÇÃO III : ASPECTOS RELACIONADOS AO PERÍODO INTRAOPERATÓRIO

\begin{tabular}{llll}
\hline Admissão ao CC: & Data $/ /$ & Hora.................... & \\
\hline Nível de consciência & (1)acordado & (2)Sonolento & (3)dormindo \\
\hline
\end{tabular}


